\title{
Dynamic analysis of wind turbine towers on flexible foundations
}

\author{
S. Adhikari ${ }^{\mathrm{a}, *}$ and S. Bhattacharya ${ }^{\mathrm{b}}$

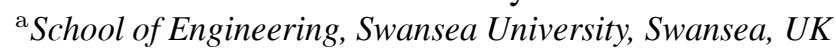 \\ ${ }^{\mathrm{b}}$ Department of Civil Engineering, University of Bristol, Bristol, UK
}

Received 3 August 2009

Revised 2 May 2010

\begin{abstract}
Offshore wind turbines are considered as an essential part to develop sustainable, alternative energy sources. The structures themselves are both slender and highly flexible, with a subsea foundation typically consisting of a single large diameter monopile. They are subject to intense wind and wave loadings, with the result that significant movement of both the exposed structure and the upper part of the monopile can occur. Although the structures are intended for design life of 25 to 30 years, very little is known about the long term behaviour of these structures. This paper characterizes the dynamic behaviour of these structures. A simplified approach has been proposed for the free vibration analysis of wind turbines taking the effect of foundation into account. The method is based on an Euler-Bernoulli beam-column with elastic end supports. The elastic end-supports are considered to model the flexible nature of the interaction of these systems with the foundation. A closed-form expression of the characteristic equation governing all the natural frequencies of the system has been derived. Theoretical developments are explained by practical numerical examples. Analytical as well as a new experimental approach has been proposed to determine the parameters for the foundation. Some design issues of wind turbine towers are discussed from the point of view of the foundation parameters.
\end{abstract}

Keywords: Wind turbine, natural frequencies, foundation stiffness, structural dynamics, offshore

\section{Introduction}

Of all the sustainable sources of energy, large offshore wind turbines may have the potential to produce reliable quantities of renewable energy. Wind turbine towers are long slender columns with a rotor and blade assembly placed on the top. These slender structures vibrate due to dynamic environmental forces and forces from the rotor vibration. Analysis of the dynamic behavior of a wind turbine tower is fundamental to its stability, performance, operation and safety. We refer the readers to a recent review paper by Jonkman [19]. The design and construction of foundations for such structures in offshore are challenging due to the dynamic nature of the offshore loading, nature of the structure (low stiffness high slenderness structure with a rotating mass at the top) and the cyclic degradation of the soil stiffness that supports the foundation. The dynamic nature of the loading on the foundation arises due to environmental loads such as the wind, wave as well as due to the rotational effects of the rotor (rotor frequency and the blade passing frequency). Figure 1 shows the various types of foundations for wind turbine towers which are either proposed or used in practice. For the sake of simplicity the tower of the wind turbine is shown as a regular column. However, in practice the tower may consist of tapered tubular column or a lattice structure or a slender offshore jacket type structure quite similar to fixed oil platforms. The types of foundations shown in Fig. 1 can be described as follows:

\footnotetext{
${ }^{*}$ Corresponding author: School of Engineering, Swansea University, Singleton Park, Swansea SA2 8PP, UK. E-mail: S.Adhikari@ swansea.ac.uk.
} 


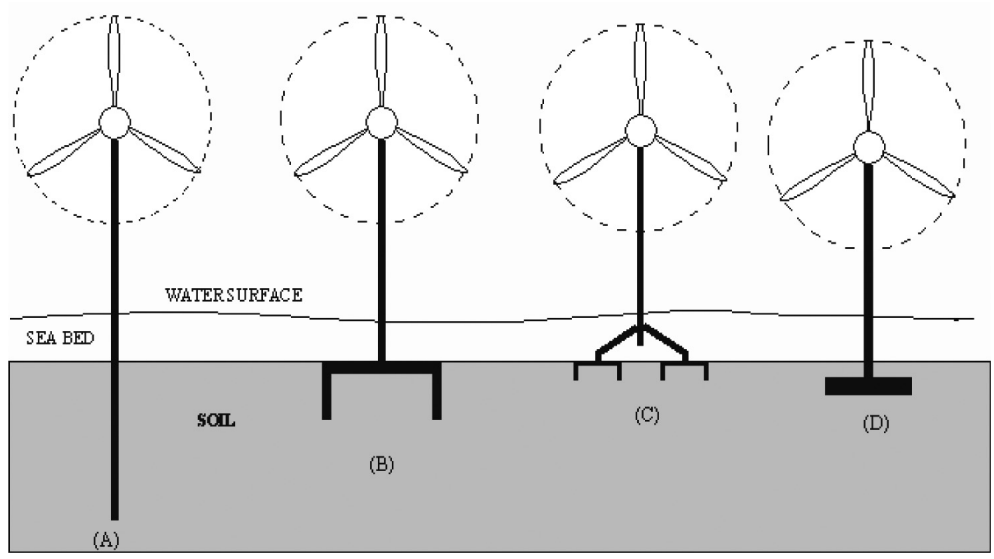

Fig. 1. Schematic diagram showing the various types of offshore foundations. A: Monopile type foundation; B: Suction caisson type of foundation; C: Multipod (tripod or tetra pod) type of foundation; D: Gravity based foundation.

1. Monopile type foundation: In this type the wind turbine tower is supported on a single long slender pipe inserted deep into the ground, see Fig. 1A. This is a conventional type of foundation installed by driving the pipe in the ground using a large hammer.

2. Suction caisson type of foundation: In this type, the wind turbine tower is supported on single hollow steel cylinder which is temporarily or permanently closed at the top by a steel top plate, see Fig. 1B. They are installed by forcing it into the seabed by means of a pump connected to the top of the pile. The idea is to create a pressure difference between the inside and the outside such that the pile is sucked into the seabed. Many details of this type of foundation can be found in reference [8].

3. Multipod (tripod or tetra pod) type of foundation: In this type, the wind turbine tower is supported by three or four individual foundations and each of these is a suction type of foundation, see Fig. 1C.

4. Gravity based foundation: This type of foundation consists of large circular or polygon shaped concrete plate type structure resting on the surface soil, see Fig. 1D.

For the design and analysis of real-life systems, detailed finite-element models are often used. A multi-physics model of a modern wind turbine with non-linear structural dynamics, fluid-structure interaction, soil-structure interaction and rotor dynamics can easily lead to computational model consisting several thousand degrees-offreedom. While such a detailed analysis can give incredible resolution of the dynamic behavior of the system, the understanding of basic physical principles which govern the overall design may be somewhat difficult to deduce from such a complex analysis. For this reason, in this paper we will focus on a simplified analysis with the aim of understanding fundamental physics which underpins the overall dynamic behavior of the system. Our approach involves the following key steps: (a) idealization of the complex system and related assumptions (b) derivation of the equation of motion (c) derivation of the boundary conditions, and (d) analytical solution of the eigenvalue problem to obtain natural frequencies of the system. In the following section these steps are described in details. The proposed method is illustrated by numerical examples.

\section{Overview of dynamic loading on the wind turbine tower}

The primary sources of dynamic load on wind turbines are as follows:

1. Excitation due to the rotor system. The rotational speed of the rotor is the primary excitation frequency and is often denoted by $1 P$, see for example Tempel and Molenaar [28]. It must be mentioned that cyclic loads will be generated due to $1 P$ frequency if there are misalignments in the rotor-nacelle system. Any inevitable out-of-balance mass will generate a harmonic force.

2. The second excitation frequency is the rotor blade passing which is given by $N_{b} P$ where $N_{b}$ is the number of rotor blades. Effectively, $2 P$ for turbine equipped with two rotor blades and $3 P$ for a three bladed rotor. 
Table 1

Material and geometric properties of the turbine tower (Tempel and Molenaar [28])

\begin{tabular}{ll}
\hline Turbine Structure Properties & Numerical values \\
\hline Length $(L)$ & $81 \mathrm{~m}$ \\
Average diameter $(D)$ & $3.5 \mathrm{~m}$ \\
Thickness $\left(t_{h}\right)$ & $0.075 \mathrm{~m}$ \\
Mass density $(\rho)$ & $7800 \mathrm{~kg} / \mathrm{m}^{3}$ \\
Young's modulus $(E)$ & $2.1 \times 10^{11} \mathrm{~Pa}$ \\
Rotational speed $(\varpi)$ & $22 \mathrm{r} . \mathrm{p} . \mathrm{m}=0.37 \mathrm{~Hz}$ \\
Top mass $(M)$ & $130,000 \mathrm{~kg}$ \\
Rated power & $3 \mathrm{MW}$ \\
\hline
\end{tabular}

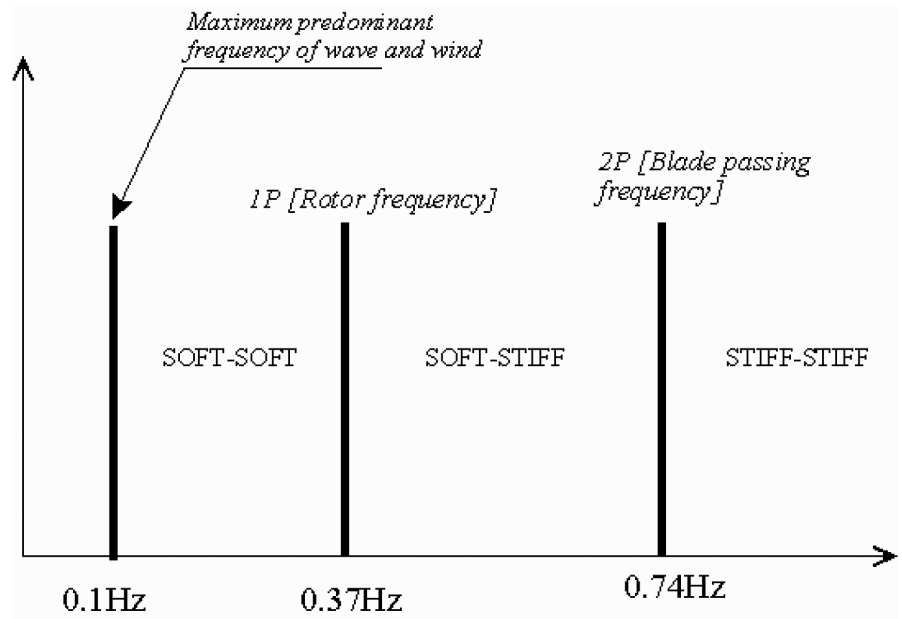

Fig. 2. Safe frequency zones, adapted and modified from Tempel and Molenaar [28].

3. Offshore ocean wave loading, often produced by wind, is also periodic in nature. Moskowitz [24] proposed wave spectra of a fully developed sea for different wind speeds $(10.3 \mathrm{~m} / \mathrm{s}$ to $20.6 \mathrm{~m} / \mathrm{s})$. The analysis shows that the range of possible frequencies of the sea lay between 0.04 and $0.10 \mathrm{~Hz}$.

4. Wind gusts and the tower shadowing effect during the blade passage the tower: These will also produce dynamic loading on the structure. Frequency spectrum of gusty wind is often generated by using frequency spectrum proposed by Davenport [9]. Based on the model, a short duration wind (1 to 60 minutes) can be regarded as a stationary random process composed of a constant mean speed and a fluctuating component (gust) modelled by power spectral density function. The dominant frequency of a gusty wind is very low compared to waves. Typically, the frequency is $0.02 \mathrm{~Hz}$.

Table 1 shows the characteristics of a 3MW constant speed two-bladed Opti-OWECS turbine.

As the frequency of the rotor is $0.37 \mathrm{~Hz}$, the value of $1 P$ is $0.37 \mathrm{~Hz}$ and the blade passing frequency is $0.74 \mathrm{~Hz}$. Figure 2 shows the various critical frequencies necessary for designing the structure. To avoid resonance type of failure, the wind turbine tower should be designed such that the first natural frequency should not be close to either $0.37 \mathrm{~Hz}$ or $0.74 \mathrm{~Hz}$ or close to the frequency of the wind and the wave at the location i.e. more than $0.1 \mathrm{~Hz}$. Therefore there are three possible intervals where the natural frequency of the structure should lie:

- The frequency can be greater than $0.74 \mathrm{~Hz}(2 P)$. This would correspond to a very stiff structure with a high natural frequency and is often referred to as Stiff-Stiff system.

- The frequency can be between $0.37 \mathrm{~Hz}(1 P)$ and $0.74 \mathrm{~Hz}(2 P)$. Such structures are often termed as Soft-stiff system.

- The frequency can be less than $0.37 \mathrm{~Hz}(1 P)$ and greater than $0.1 \mathrm{~Hz}$. Such structures are often termed as Soft-Soft system. 


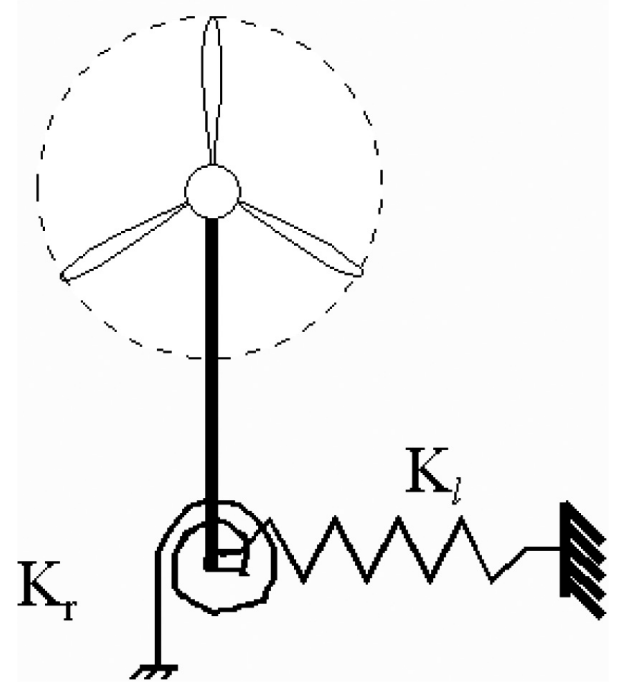

Fig. 3. The mechanical idealization of the wind turbine considered in this paper. The foundation is modelled by a rotational spring $\left(k_{r}\right)$ and a lateral spring $\left(k_{l}\right)$.

It is therefore essential to perform a free vibration analysis of the structure considering the flexibility of the foundation. The comparison of the natural period of the structure with the various loading frequencies (Fig. 2) can provide us useful information on the dynamic sensitivity. Often the first natural frequency of a structure is considered as the primary indicator of the dynamic responses. Tempel and Molenaar [28] proposed a method to carry out dynamic analysis of a flexible wind turbine system. The wind turbine is modelled as a flagpole of length $L$, mass per unit length $m$ having bending stiffness $E I$ with a top mass $M$. The flagpole is assumed to be fixed at the bottom. The first natural frequency $\left(f_{1}\right)$ of the system is proposed as

$$
f_{1} \approx \sqrt{\frac{3.04 E I}{(M+0.227 m L) 4 \pi^{2} L^{3}}} .
$$

While Eq. (1) is simple to use, it does not consider the flexibility of the foundation and stiffness softening effect due to the axial load arising due to the mass of the rotor and blade system.

The aim of the paper is therefore to advance the modelling by considering the flexibility of the foundation and also the effect of the axial load. At the same time, the emphasis has been placed on the simplicity of the approach so that a complex finite element analysis is not necessary. The new results to be derived may be used in the initial design stage where crucial decisions need to be taken quickly. Once this is done, the final design can be fine-tuned using high-fidelity computational design and analysis tools. In the current paper, the wind turbine tower is idealized as shown in Fig. 3. The foundation is modelled by two springs denoted by $k_{r}$ (rotational spring) and $k_{l}$ (lateral spring). Each of the foundations described in Fig. 1 can be described by these two springs with suitable parameter values.

\section{Equation of motion and boundary conditions}

We consider a typical wind turbine tower as shown in Fig. 4. This system is idealized by an Euler Bernoulli beam and the idealization process is explained in the diagram. The bending stiffness of the beam is $E I(x)$ and it is attached to the foundation. Here $x$ is the spatial coordinate, starting at the bottom and moving along the height of the structure. The interaction of the structure with the foundation is modeled using two springs. The rotational spring with spring stiffness $k_{r}$ and the lateral spring with spring stiffness $k_{l}$ constrains the system at the bottom $(x=0)$. The beam has a top mass with rotary inertia $J$ and mass $M$. This top mass is used to idealize the rotor and blade system. The mass per unit length of the beam is $m(x), r(x)$ is the radius of gyration and the beam is subjected to a constant compressive axial load $P=M g$. The force $P$ in general can be a function of time due to the rotational 


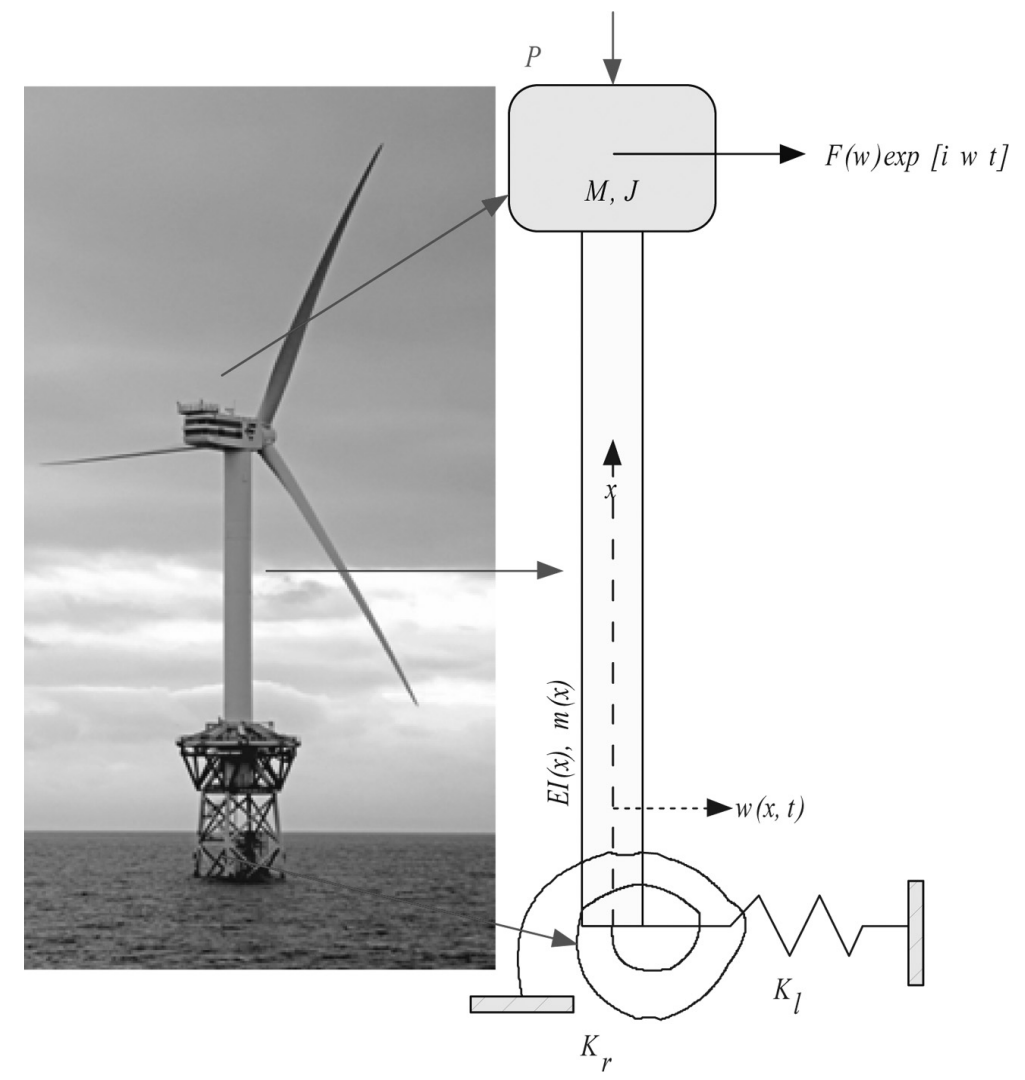

Fig. 4. Idealization of a wind turbine using Euler Bernoulli beam with a top mass. Flexible springs are assumed to model the foundation-structure interaction. The weight of the rotor-hub and blades are assumed to be $P$. The forcing due to the rotation of the blades is assumed to be harmonic in nature with frequency $\varpi$.

motion of the hub. However, in this paper we assume this as a constant considering the angular velocity of the blades is small. Although the motivation of this study is arising from the large offshore wind turbines shown in Figs 1 and 4 , the analytical formulation proposed here is not restricted to offshore wind turbines. With suitable values of $k_{r}$ and $k_{l}$, this analysis can be applied on onshore wind turbines also.

The equation of motion of the beam is given by (see for example the books by Géradin and Rixen [15] and Inman [18]):

$$
\begin{aligned}
& \frac{\partial^{2}}{\partial x^{2}}\left(E I(x) \frac{\partial^{2} w(x, t)}{\partial x^{2}}\right)+\frac{\partial}{\partial x}\left(P(x) \frac{\partial w(x, t)}{\partial x}\right)-\frac{\partial}{\partial x}\left(m r^{2}(x) \frac{\partial \ddot{w}(x, t)}{\partial x^{2}}\right) \\
& +m \ddot{w}(x, t)=f(x, t) .
\end{aligned}
$$

Here $w(x, t)$ is the transverse deflection of the beam, $t$ is time, $(\bullet)$ denotes derivative with respect to time and $f(x, t)$ is the applied time depended load on the beam. The height of the structure is considered to be $L$. Equation (2) is a fourth-order partial differential Equation [20] and has been used extensively in literature for various problems (see for example, references $[3,6,10-13,16,17,25,29]$ ). Our central aim is to obtain the natural frequency of the system. Here we develop an approach based on the non-dimensionalisation of the equation of motion (2).

There are various forces acting on the wind turbine structure such as the forcing due to rotor imbalance and wind loading. The resultant force can be expressed as harmonics of the frequency of revolution of the blades and in general can be represented as

$$
f(x, t)=f_{0}(x) \exp [i \omega t]
$$

The forcing frequency $\omega$ can be related to the rotor frequency or blade passing frequency and the number of blades. The function $f_{0}(x)$ is the resultant forcing amplitude on the tower as a function of $x$. The response $w(x, t)$ is 
assumed to be in the same plane as the resultant forcing. Although we give the mathematical form of the forcing on the structure, this expression will not be explicitly used in the paper because here we are primarily interested in the natural frequency of the system. However, as will be seen later, the origin of the frequency content of the forcing given by Eq. (3) is important from the point of view of resonance and instability of the system.

Equation (2) is a quite general equation. It is possible to consider any variation in the bending stiffness $E I(x)$ and mass density $m(x)$ of the structure with height (such as a tapered column). Consideration of such variation normally leads to the case where exact closed-form solutions are impossible to obtain due to the complex nature of the resulting equations. For the simplicity, here we assume constant equivalent properties. Assuming that the properties are not changing with $x$, Eq. (2) can be simplified as

$$
E I \frac{\partial^{4} w(x, t)}{\partial x^{4}}+P \frac{\partial^{2} w(x, t)}{\partial x^{2}}-m r^{2} \frac{\partial^{2} \ddot{w}(x, t)}{\partial x^{2}}+m \ddot{w}(x, t)=f_{0}(x) \exp [i \omega t] .
$$

The four boundary conditions associated with this equation can be expressed as

- Bending moment at $x=0$ :

$$
E I \frac{\partial^{2} w(x, t)}{\partial x^{2}}-k_{r} \frac{\partial w(x, t)}{\partial x}=\left.0\right|_{x=0} \text { or } E I w^{\prime \prime}(0, t)-k_{r} w^{\prime}(0, t)=0 .
$$

- Shear force at $x=0$ :

$$
\begin{aligned}
& \quad E I \frac{\partial^{3} w(x, t)}{\partial x^{3}}+P \frac{\partial w(x, t)}{\partial x}+k_{l} w(x, t)-m r^{2} \frac{\partial \ddot{w}(x, t)}{\partial x}=\left.0\right|_{x=0} \\
& \text { or } E I w^{\prime \prime \prime}(0, t)+P w^{\prime}(0, t)+k_{l} w(0, t)-m r^{2} \frac{\partial \ddot{w}(0, t)}{\partial x}=0 .
\end{aligned}
$$

- Bending moment at $x=L$ :

$$
E I \frac{\partial^{2} w(x, t)}{\partial x^{2}}+J \frac{\partial \ddot{w}(x, t)}{\partial x}=\left.0\right|_{x=L} \text { or } E I w^{\prime \prime}(L, t)+J \frac{\partial \ddot{w}(L, t)}{\partial x}=0 .
$$

- Shear force at $x=L$ :

$$
\begin{aligned}
& \quad E I \frac{\partial^{3} w(x, t)}{\partial x^{3}}+P \frac{\partial w(x, t)}{\partial x}-M \ddot{w}(x, t)-m r^{2} \frac{\partial \ddot{w}(x, t)}{\partial x}=\left.0\right|_{x=L} \\
& \text { or } E I w^{\prime \prime \prime}(L, t)+P w^{\prime}(L, t)-M \ddot{w}(L, t)-m r^{2} \frac{\partial \ddot{w}(L, t)}{\partial x}=0 .
\end{aligned}
$$

Assuming harmonic solution (the separation of variable) we have

$$
w(x, t)=W(\xi) \exp [i \omega t], \quad \xi=x / L .
$$

Substituting this in the equation of motion and the boundary conditions, Eqs (4)-(8) results

$$
\begin{aligned}
& \frac{E I}{L^{4}} \frac{\partial^{4} W(\xi)}{\partial \xi^{4}}+\frac{P}{L^{2}} \frac{\partial^{2} W(\xi)}{\partial \xi^{2}}-m \omega^{2} W(\xi)+\frac{m r^{2} \omega^{2}}{L^{2}} \frac{\partial^{2} W(\xi)}{\partial \xi^{2}}=f_{0}(\xi L) \\
& \frac{E I}{L^{2}} W^{\prime \prime}(0)-\frac{k_{r}}{L} W^{\prime}(0)=0 \\
& \frac{E I}{L^{3}} W^{\prime \prime \prime}(0)+\frac{P}{L} W^{\prime}(0)+k_{l} W(0)+\frac{m r^{2} \omega^{2}}{L} W^{\prime}(0)=0 \\
& \frac{E I}{L^{2}} W^{\prime \prime}(1)-\frac{\omega^{2} J}{L} W^{\prime}(1)=0 \\
& \frac{E I}{L^{3}} W^{\prime \prime \prime}(1)+\frac{P}{L} W^{\prime}(1)+\omega^{2} M W(1)+\frac{m r^{2} \omega^{2}}{L} W^{\prime}(1)=0 .
\end{aligned}
$$

It is convenient to express these equations in terms of non-dimensional parameters by elementary rearrangements as 


$$
\begin{aligned}
& \frac{\partial^{4} W(\xi)}{\partial^{4} \xi^{4}}+\widetilde{\nu} \frac{\partial^{2} W(\xi)}{\partial \xi^{2}}-\Omega^{2} W(\xi)=p_{L}(\xi L) \\
& W^{\prime \prime}(0)-\eta_{r} W^{\prime}(0)=0 \\
& W^{\prime \prime \prime}(0)+\widetilde{\nu} W^{\prime}(0)+\eta_{l} W(0)=0 \\
& W^{\prime \prime}(1)-\beta \Omega^{2} W^{\prime}(1)=0 \\
& W^{\prime \prime \prime}(1)+\widetilde{\nu} W^{\prime}(1)+\alpha \Omega^{2} W(1)=0
\end{aligned}
$$

where

$$
\begin{aligned}
\widetilde{\nu} & =\nu+\mu^{2} \Omega^{2} \\
\nu & =\frac{P L^{2}}{E I} \quad \text { (nondimensional axial force) } \\
\eta_{r} & =\frac{k_{r} L}{E I} \quad \text { (nondimensional rotational foundation stiffness) } \\
\eta_{l} & =\frac{k_{l} L^{3}}{E I} \quad \text { (nondimensional lateral foundation stiffness) } \\
\Omega^{2} & =\omega^{2} \frac{m L^{4}}{E I} \quad \text { (nondimensional frequency parameter) } \\
\alpha & =\frac{M}{m L} \quad(\text { mass ratio) } \\
\beta & =\frac{J}{m L^{3}} \quad \text { (nondimensional rotary inertia) } \\
\mu & =\frac{r}{L} \quad(\text { nondimensional radius of gyration) } \\
\text { and } \quad p_{L}(\xi L) & =\frac{f_{0}(\xi L) L^{4}}{E I} \quad \text { (normalized forcing amplitude) }
\end{aligned}
$$

In together, the parameters $\eta_{r}$ and $\eta_{l}$ will be called as the soil-structure interaction parameters as they solely quantify the interactions between the soil and the structure within the scope of the proposed model. For most columns $\mu=r / L \ll 1$ so that $\mu^{2} \approx 0$. As a result for low frequency vibration one expects $\widetilde{\nu} \approx \nu$. For notational convenience we define the natural frequency scaling parameter

$$
c_{0}=\sqrt{\frac{E I}{m L^{4}}} .
$$

Using this, from Eq. (24) the natural frequencies of the system can be obtained as

$$
\omega_{j}=\Omega_{j} c_{0} ; \quad j=1,2,3, \cdots
$$

\section{Equation of the natural frequencies}

Natural frequencies of the system can be obtained from the 'free vibration problem' by considering no force on the system. Therefore, we consider $p_{L}=0$ in the subsequent analysis. Assuming a solution of the form

$$
W(\xi)=\exp \{\lambda \xi\}
$$

and substituting in the equation of motion (15) results

$$
\lambda^{4}+\widetilde{\nu} \lambda^{2}-\Omega^{2}=0
$$

This equation is often known as the dispersion relationship. This is the equation governing the natural frequencies of the beam. Solving this equation for $\lambda^{2}$ we have 


$$
\begin{aligned}
\lambda^{2} & =-\frac{\widetilde{\nu}}{2} \pm \sqrt{\left(\frac{\widetilde{\nu}}{2}\right)^{2}+\Omega^{2}} \\
& =-\left(\sqrt{\left(\frac{\widetilde{\nu}}{2}\right)^{2}+\Omega^{2}}+\frac{\widetilde{\nu}}{2}\right), \quad\left(\sqrt{\left(\frac{\widetilde{\nu}}{2}\right)^{2}+\Omega^{2}}-\frac{\widetilde{\nu}}{2}\right) .
\end{aligned}
$$

Because $\widetilde{\nu}^{2}$ and $\Omega^{2}$ are always positive quantities, both roots are real with one negative and one positive root. Therefore, the four roots can be expressed as

$$
\lambda= \pm \mathrm{i} \lambda_{1}, \quad \pm \lambda_{2}
$$

where

$$
\begin{aligned}
\lambda_{1} & =\left(\sqrt{\left(\frac{\widetilde{\nu}}{2}\right)^{2}+\Omega^{2}}+\frac{\widetilde{\nu}}{2}\right)^{1 / 2} \\
\text { and } \quad \lambda_{2} & =\left(\sqrt{\left(\frac{\widetilde{\nu}}{2}\right)^{2}+\Omega^{2}}-\frac{\widetilde{\nu}}{2}\right)^{1 / 2} .
\end{aligned}
$$

In view of the roots in Eq. (34), the solution $W(\xi)$ can be expressed as

$$
\begin{aligned}
W(\xi) & =a_{1} \sin \lambda_{1} \xi+a_{2} \cos \lambda_{1} \xi+a_{3} \sinh \lambda_{2} \xi+a_{4} \cosh \lambda_{2} \xi \\
\text { or } W(\xi) & =\mathbf{s}^{T}(\xi) \mathbf{a}
\end{aligned}
$$

where the vectors

$$
\begin{aligned}
\mathbf{s}(\xi) & =\left\{\sin \lambda_{1} \xi, \cos \lambda_{1} \xi, \sinh \lambda_{2} \xi, \cosh \lambda_{2} \xi\right\}^{T} \\
\text { and } \quad \mathbf{a} & =\left\{a_{1}, a_{2}, a_{3}, a_{4}\right\}^{T} .
\end{aligned}
$$

Applying the boundary conditions in Eqs (16) - (19) on the expression of $W(\xi)$ in (37) we have

$$
\mathbf{R a}=\mathbf{0}
$$

where the matrix

$$
\begin{aligned}
& \mathbf{R}=\left[\begin{array}{cc}
s_{1}^{\prime \prime}(0)-\eta_{r} s_{1}^{\prime}(0) & s_{2}^{\prime \prime}(0)-\eta_{r} s_{2}^{\prime}(0) \\
s_{1}^{\prime \prime \prime}(0)+\widetilde{\nu} s_{1}^{\prime}(0)+\eta_{l} s_{1}(0) & s_{2}^{\prime \prime \prime}(0)+\widetilde{\nu} s_{2}^{\prime}(0)+\eta_{l} s_{2}(0) \\
s_{1}^{\prime \prime}(1)-\beta \Omega^{2} s_{1}^{\prime}(1) & s_{2}^{\prime \prime}(1)-\beta \Omega^{2} s_{2}^{\prime}(1) \\
s_{1}^{\prime \prime \prime}(1)+\widetilde{\nu} s_{1}^{\prime}(1)+\alpha \Omega^{2} s_{1}(1) & s_{2}^{\prime \prime \prime}(1)+\widetilde{\nu} s_{2}^{\prime}(1)+\alpha \Omega^{2} s_{2}(1)
\end{array}\right. \\
& \left.\begin{array}{cc}
s_{3}^{\prime \prime}(0)-\eta_{r} s_{3}^{\prime}(0) & s_{4}^{\prime \prime}(0)-\eta_{r} s_{4}^{\prime}(0) \\
s_{3}^{\prime \prime \prime}(0)+\widetilde{\nu} s_{3}^{\prime}(0)+\eta_{l} s_{3}(0) & s_{4}^{\prime \prime \prime}(0)+\widetilde{\nu} s_{4}^{\prime}(0)+\eta_{l} s_{4}(0) \\
s_{3}^{\prime \prime}(1)-\beta \Omega^{2} s_{3}^{\prime}(1) & s_{4}^{\prime \prime}(1)-\beta \Omega^{2} s_{4}^{\prime}(1) \\
s_{3}^{\prime \prime \prime}(1)+\widetilde{\nu} s_{3}^{\prime}(1)+\alpha \Omega^{2} s_{3}(1) & s_{3}^{\prime \prime \prime}(1)+\widetilde{\nu} s_{3}^{\prime}(1)+\alpha \Omega^{2} s_{3}(1)
\end{array}\right] .
\end{aligned}
$$

Substituting functions $s_{j}(\xi), j=1, \cdots, 4$ from Eq. (38) and simplifying we obtain

$$
\begin{gathered}
\mathbf{R}=\left[\begin{array}{cc}
-\lambda_{1} \eta_{r} & -\lambda_{1}^{2} \\
\lambda_{1}^{3}+\nu \lambda_{1} & \eta_{l} \\
-\sin \left(\lambda_{1}\right) \lambda_{1}{ }^{2}-\Omega^{2} \beta \cos \left(\lambda_{1}\right) \lambda_{1} & -\cos \left(\lambda_{1}\right) \lambda_{1}{ }^{2}+\Omega^{2} \beta \sin \left(\lambda_{1}\right) \lambda_{1} \\
-\cos \left(\lambda_{1}\right) \lambda_{1}{ }^{3}+\widetilde{\nu} \cos \left(\lambda_{1}\right) \lambda_{1}+\Omega^{2} \alpha \sin \left(\lambda_{1}\right) \sin \left(\lambda_{1}\right) \lambda_{1}{ }^{3}-\widetilde{\nu} \sin \left(\lambda_{1}\right) \lambda_{1}+\Omega^{2} \alpha \cos \left(\lambda_{1}\right) \\
-\lambda_{2} \eta_{r} & \lambda_{2}^{2} \\
\lambda_{2}^{3}+\nu \lambda_{2} & \eta_{l} \\
\sinh \left(\lambda_{2}\right) \lambda_{2}{ }^{2}-\Omega^{2} \beta \cosh \left(\lambda_{2}\right) \lambda_{2} & \cosh \left(\lambda_{2}\right) \lambda_{2}{ }^{2}-\Omega^{2} \beta \sinh \left(\lambda_{2}\right) \lambda_{2} \\
\cosh \left(\lambda_{2}\right) \lambda_{2}{ }^{3}+\widetilde{\nu} \cosh \left(\lambda_{2}\right) \lambda_{2}+\Omega^{2} \alpha \sinh \left(\lambda_{2}\right) \sinh \left(\lambda_{2}\right) \lambda_{2}{ }^{3}+\widetilde{\nu} \sinh \left(\lambda_{2}\right) \lambda_{2}+\Omega^{2} \alpha \cosh \left(\lambda_{2}\right)
\end{array}\right]
\end{gathered}
$$


The constant vector in Eq. (40) cannot be zero. Therefore, the equation governing the natural frequencies is given by

$$
|\mathbf{R}|=0 .
$$

This is a transcendental equation. The natural frequencies can be obtained by solving Eq. (43) for $\Omega$. Denoting the solution of this equation as $\Omega_{j}$, the actual natural frequencies of the system can be obtained using Eq. (30). Due to the nonlinearity of this transcendental equation it need to be solved numerically. In this paper Eq. (43) has been translated to Matlab ${ }^{\circledR}$ and has been solved numerically.

\subsection{Special cases}

Equation (43) is quite general as it considers axial load, elastic end restraints, mass and rotary inertia of the rotor. Several interesting special cases can be obtained from this expression. These special cases are useful from the point of view of both analytical validation and physical understandings.

- Standard cantilever column: fixed support without any top mass, rotary inertia and axial force:

For this case $\beta=0, \alpha=0, \mu=0$ and $\nu=0$. From the dispersion relationship in (32) observe that for this case $\lambda_{1}=\lambda_{2}=\sqrt{\Omega}=\omega \sqrt{\frac{m L^{4}}{E I}}=\lambda$ (say). Since the bottom of the column is fixed, the stiffness parameters $\eta_{r}$ and $\eta_{l}$ approach to infinity. Substituting these in Eq. (43) and simplifying we obtain the frequency equation as

$$
1+\cos (\lambda) \cosh (\lambda)=0 .
$$

This matches exactly with the frequency equation for a standard cantilever (see the book by Meirovitch [23]).

- Cantilever column with a top mass: fixed support without any rotary inertia and axial force:

This case has been considered by Tempel and Molenaar [28]. For this case $\eta=0, \beta=0$, and $\nu=0$. From the dispersion relationship in (32) observe that for this case again $\lambda_{1}=\lambda_{2}=\lambda$ (say). Substituting these in Eq. (43), taking the limit $\eta_{r}, \eta_{l} \rightarrow \infty$ and simplifying we obtain the frequency equation as

$$
(-\sin (\lambda) \cosh (\lambda)+\cos (\lambda) \sinh (\lambda)) \alpha \lambda+\cos (\lambda) \cosh (\lambda)+1=0 .
$$

If we substitute $\alpha=0$ in this equation, we retrieve the standard cantilever case obtained in Eq. (44).

- Cantilever column with a top mass and rotary inertia: fixed support without axial force:

For this case only $\eta=0$ and $\nu=0$ and we also have $\lambda_{1}=\lambda_{2}=\lambda$ (say). Substituting these in Eq. (43), taking the limit $\eta_{r}, \eta_{l} \rightarrow \infty$ and simplifying we obtain the frequency equation as

$$
\begin{array}{r}
(-\cos (\lambda) \cosh (\lambda)+1) \alpha \beta \lambda^{4}+(-\cos (\lambda) \sinh (\lambda)-\sin (\lambda) \cosh (\lambda)) \beta \lambda^{3} \\
+(-\sin (\lambda) \cosh (\lambda)+\cos (\lambda) \sinh (\lambda)) \alpha \lambda+\cos (\lambda) \cosh (\lambda)+1=0 .
\end{array}
$$

If we substitute $\beta=0$ in this equation, we retrieve the case obtained in Eq. (45).

\section{Numerical example}

In this section we aim to understand the analytical expressions developed in the last section. First we determine the relevant non-dimensional parameters appearing in the equations derived the paper. We focus our attention on the effect of $\nu$ and the non-dimensional foundation stiffness parameters $\eta_{r}$ and $\eta_{l}$ on the first-natural frequency. For this reason, the numerical results are presented as a function of $\nu, \eta_{r}$ and $\eta_{l}$. These three parameters are considered because the boundary conditions and the load on the turbine are the crucial design issues for the overall system.

The non-dimensional mass ratio can be obtained as

$$
\alpha=\frac{M}{m L}=\frac{P}{g m L}=\frac{P L^{2}}{E I}\left(\frac{E I}{g m L^{3}}\right)=\nu\left(\frac{E I}{m L^{4}}\right) L / g=\nu c_{0}^{2} L / g
$$

We consider the rotary inertia of the blade assembly $J=0$. This assumption may not be a significant limitation for this example as the center of inertia is very close to the point of attachment of the rotor-blade system with the column. 
In this example we have used the data of a wind turbine given by Tempel and Molenaar [28]. The numerical values of the main parameters are summarized in Table 1 shown before. The moment of inertia of the circular cross section can be obtained as

$$
I=\frac{\pi}{64} D^{4}-\frac{\pi}{64}\left(D-2 t_{h}\right)^{4} \approx \frac{1}{8} \pi D^{3} t_{h}=0.6314 m^{4}
$$

The mass density per unit length of the system can be obtained as

$$
m=\rho A \approx \rho \pi D t_{h} / 2=3.1817 \times 10^{3} \mathrm{~kg} / \mathrm{m}
$$

Using these, the mass ratio $\alpha=0.2495$ and the nondimensional axial force $\nu=0.0652$. We also obtain the natural frequency scaling parameter can be obtained as

$$
c_{0}=\sqrt{\frac{E I}{m L^{4}}}=0.9682 \mathrm{~s}^{-1} .
$$

The radius of gyration of the wind turbine is given by

$$
r=\sqrt{\frac{I}{A}}=\frac{1}{4} \sqrt{D^{2}+\left(D-2 t_{h}\right)^{2}} \approx \frac{D}{2 \sqrt{2}}=1.2374 m
$$

Therefore, the nondimensional radius of gyration $\mu=r / L=0.0151$. From Eq. (20) we therefore have

$$
\widetilde{\nu}=\nu+2.2844 \times 10^{-4} \Omega^{2} \approx \nu
$$

The values of the foundation stiffness parameters were not given. For the fixed support, the values of $\eta_{r}$ and $\eta_{l}$ will be infinity. Therefore, we will use $\eta_{r}$ and $\eta_{l}$ as variable parameters and try to understand how they affect the overall behavior of the system. The determination of $\eta_{r}$ and $\eta_{l}$ will be discussed in the next section.

We substitute the derived constants in Eqs (35) and (36) to obtain $\lambda_{1}$ and $\lambda_{2}$. Substituting them in Eq. (43) we solve for the nondimensional first natural frequency $\Omega_{1}$. From this we obtain the circular frequency (in Hz) as

$$
f_{1}=\frac{\omega_{1}}{2 \pi}=\frac{\Omega_{1} c_{0}}{2 \pi}
$$

For the majority of applications the first natural frequency is the most important. Higher natural frequencies can however be obtained by solving Eq. (43). The variation of the first natural frequency of the wind turbine with respect to the axial load for different values of nondimensional rotational foundation stiffness and four fixed values of the nondimensional lateral stiffness are shown in Fig. 5. A similar plot, but this time for different values of $\eta_{r}$ is shown in Fig. 6 for further understanding. Since these plots are in terms of the generalized non-dimensional quantities, they are applicable to any turbine towers which can be modeled within the scope of the approximations discussed before. The natural frequency of the system increases with the increasing values of the stiffness parameters $\eta_{r}$ and $\eta_{l}$. This is due to the fact that the increase in the rotational and lateral stiffness properties stabilizes the system. Note that after certain values of $\eta_{r}$ and $\eta_{l}$ (typically above 100), a further increase in their values do not change the natural frequency. This is because after these values, the foundation structure interaction can be essentially considered as fixed so that further increase in $\eta_{r}$ and/or $\eta_{l}$ has no effect. The natural frequency of the system decreases with the increasing value of $\nu$. This is expected as the increase in the downward axial force essentially drives the system closer to buckling. The zero natural frequency corresponding to very small value of the rotational stiffness in Fig. 6(a) suggests that the system has buckled. In these figures we have plotted the real data corresponding to the system (marked by '*'). The design should be such that the natural frequency of the system should avoid the rotor and blade passing frequency.

The variation of the first natural frequency of the wind turbine with respect to the nondimensional rotational foundation stiffness for different values of axial force and four fixed values of the nondimensional lateral stiffness is shown in Fig. 7. A similar plot, showing the variation of the first natural frequency with respect to the nondimensional lateral foundation stiffness for different values of axial force and four fixed values of the nondimensional rotational stiffness is given by Fig. 8. In the same diagrams the rotor frequency is shown by a dashed line. The design should 


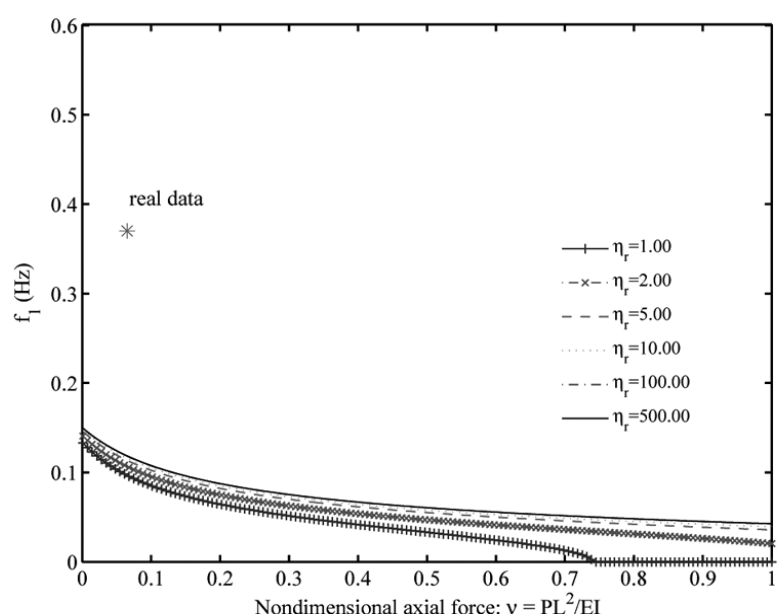

(a) $\eta_{l}=1$

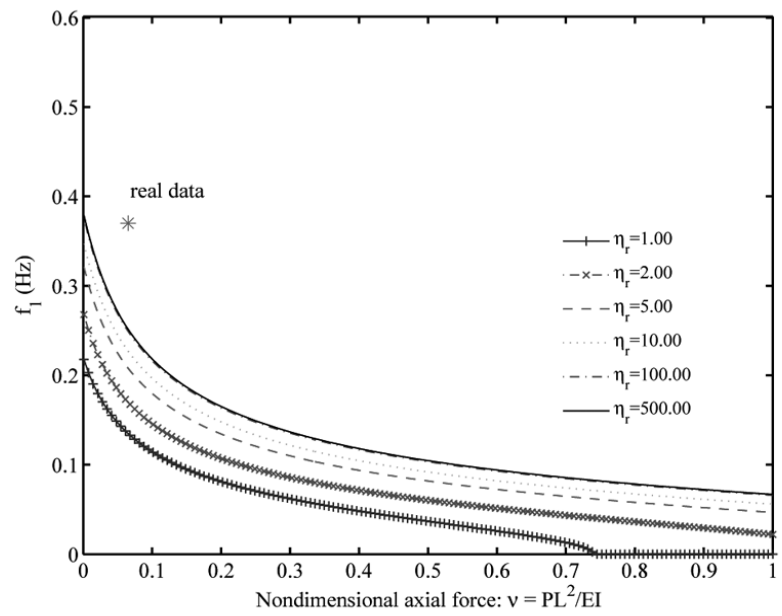

(c) $\eta_{l}=10$

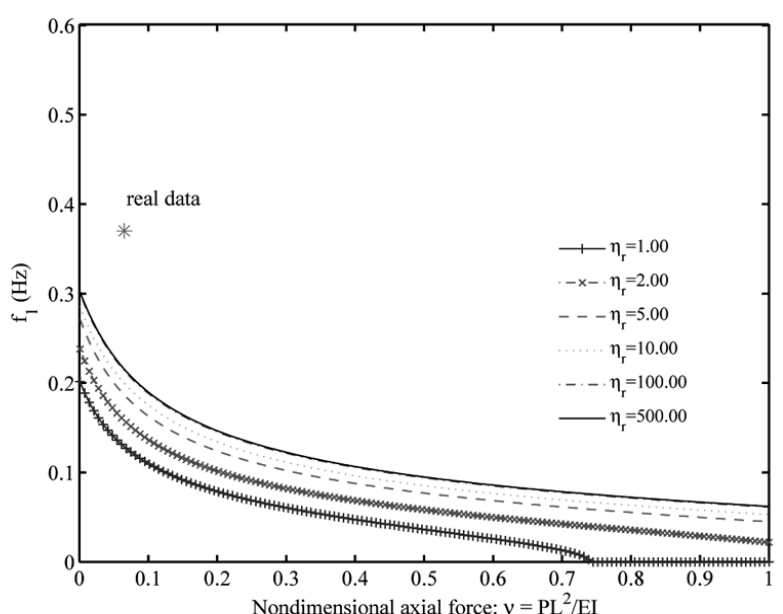

(b) $\eta_{l}=5$

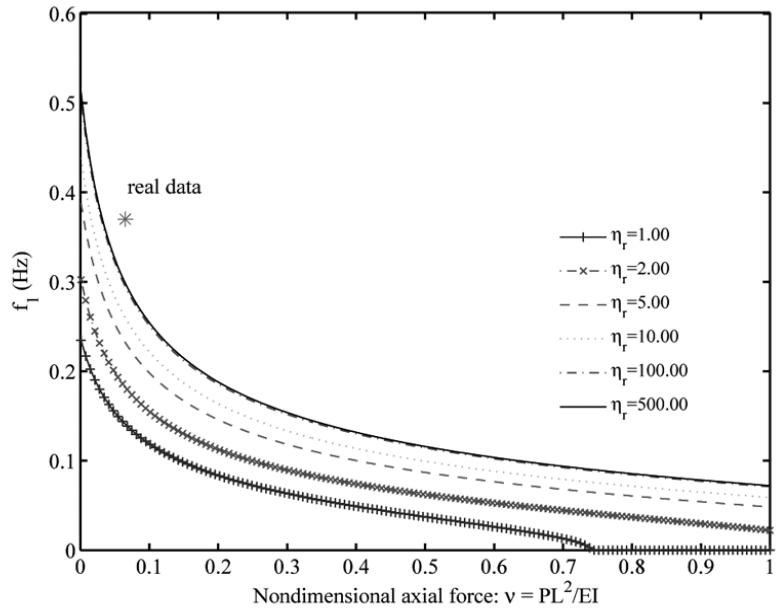

(d) $\eta_{l}=100$

Fig. 5. The variation of the first natural frequency of the wind turbine with respect to the nondimensional axial load $\nu$ for different values of nondimensional rotational foundation stiffness $\eta_{r}$. Four fixed values of the nondimensional lateral stiffness $\eta_{l}$ are considered in the four subplots. The data from the example ( $\varpi=0.37 \mathrm{~Hz}$ and $\nu=0.0315)$ is shown by a ' $*$ ' in the diagram.

be such that the natural frequency of the system must always be far from this line. From this criteria one can decide which parameter values should be avoided for a safe design.

In Fig. 9, the overall variation of the first natural frequency of the wind turbine with respect to both nondimensional rotational foundation stiffness and axial load is shown in a 3D plot. Four fixed values of the nondimensional lateral stiffness $\eta_{l}$ are considered in the four subplots. The interesting feature to observe from this plot are (a) the rapid and sharp 'fall' in the natural frequency for small values of $\eta_{r}$ and relative flatness for values of $\eta_{r}$ approximately over 50 , and (b) extremely high sensitivity for lower values of $\nu$. The parameter $\eta_{l}$ has an overall 'scaling effect' of the natural frequency. Higher values of the stiffness corresponds to higher values of the natural frequency as expected. If discretized model was used, the natural frequencies would have been obtained from a matrix eigenvalue problem. The role of parameter variability as studied here can be understood using more general eigenvalue sensitivity analysis (see for example [1,2]). In Fig. 10, the overall variation of the first natural frequency with respect to both the nondimensional foundation stiffness parameters is shown in a $3 \mathrm{D}$ plot. Four fixed values of the nondimensional axial load $\nu$ are considered in the four subplots. It can be seen that lower values of $\nu$ corresponds to higher values of the natural frequency as seen in the previous figures. 


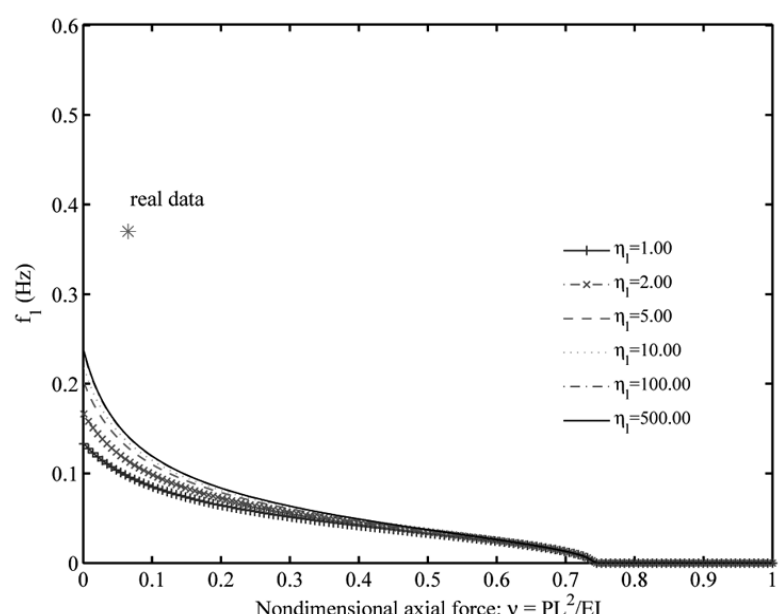

(a) $\eta_{r}=1$

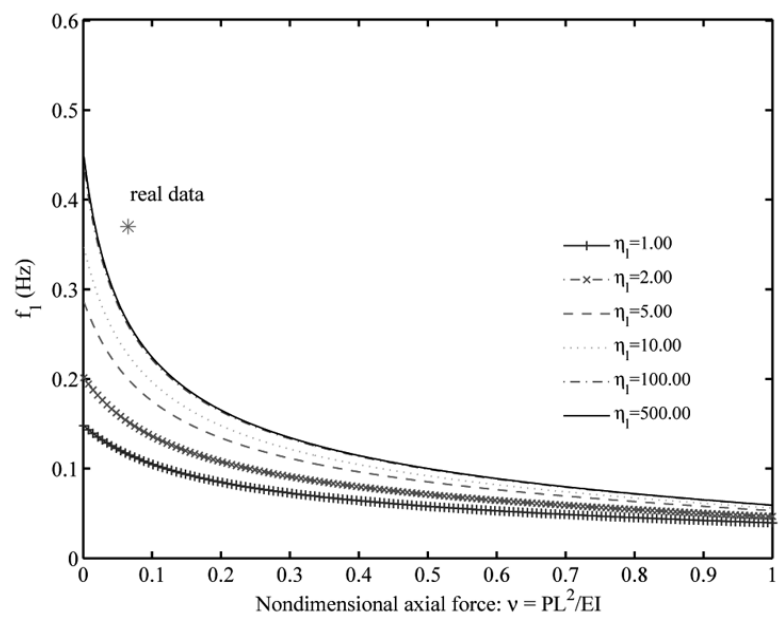

(c) $\eta_{r}=10$

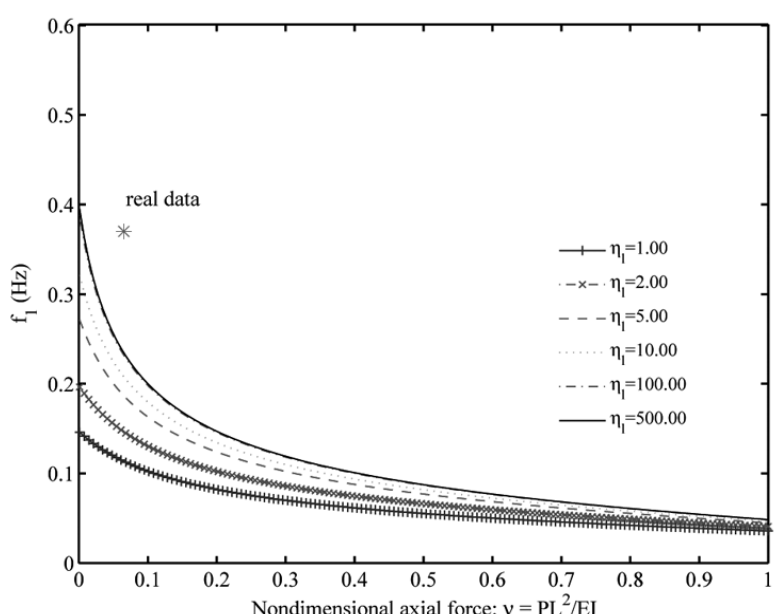

(b) $\eta_{r}=5$

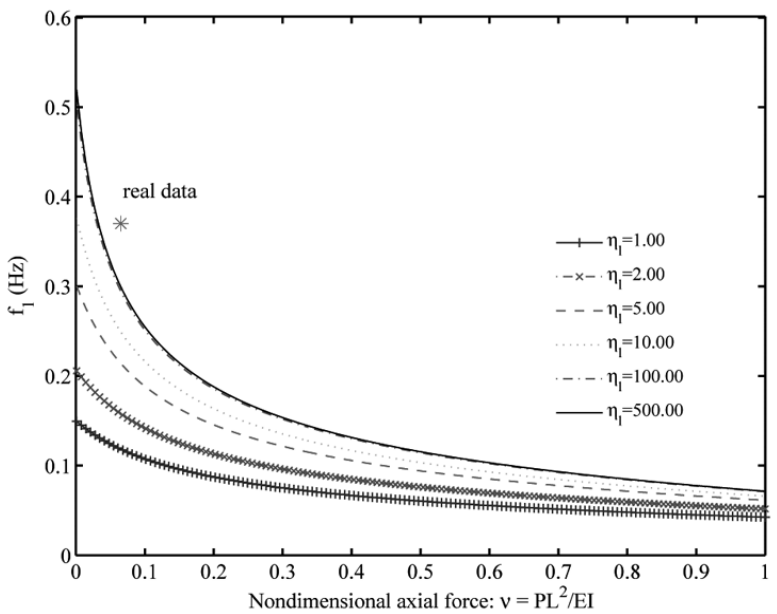

(d) $\eta_{r}=100$

Fig. 6. The variation of the first natural frequency of the wind turbine with respect to the nondimensional axial load $\nu$ for different values of nondimensional lateral foundation stiffness $\eta_{l}$. Four fixed values of the nondimensional rotational stiffness $\eta_{r}$ are considered in the four subplots. The data from the example ( $\varpi=0.37 \mathrm{~Hz}$ and $\nu=0.0315$ ) is shown by a '*' in the diagram.

These plots can be used to understand the overall design of the system.

\section{Determination of the soil-structure interaction parameters}

Numerical results in the previous section show the influence of the soil-structure interaction parameters $\eta_{r}$ and $\eta_{l}$ on the natural frequency of the system. In order to apply the proposed method, one needs to obtain $\eta_{r}$ and $\eta_{l}$ for real wind turbine structures. In this section we outline an experimental approach and two analytical approaches. The analytical approaches have been applied to few real-life wind turbines.

\subsection{Experiential approach}

A 1:100 scale model of a Vestas V90 3MW wind turbine which has a swept area diameter of $90 \mathrm{~m}$ and a nacelle height of 105 metres has been developed in BLADE laboratory of the University of Bristol (see Fig. 11 for details). 


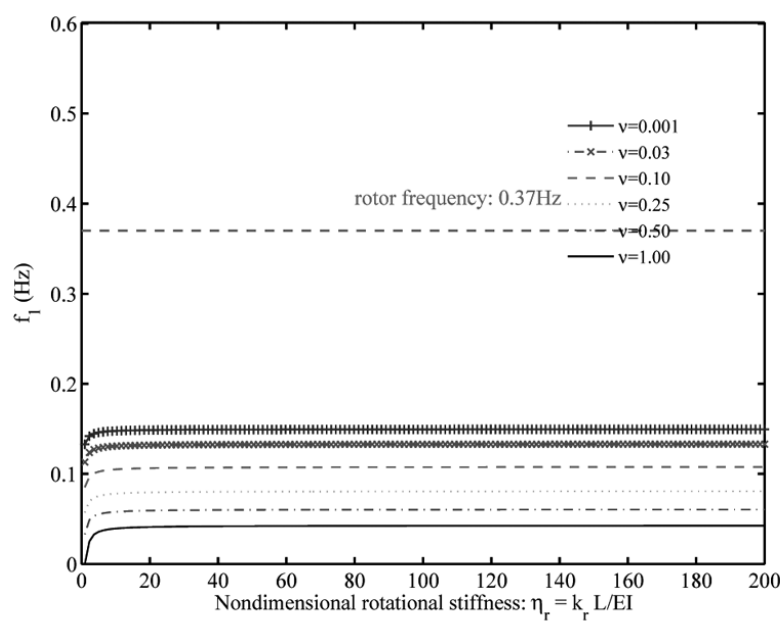

(a) $\eta_{l}=1$

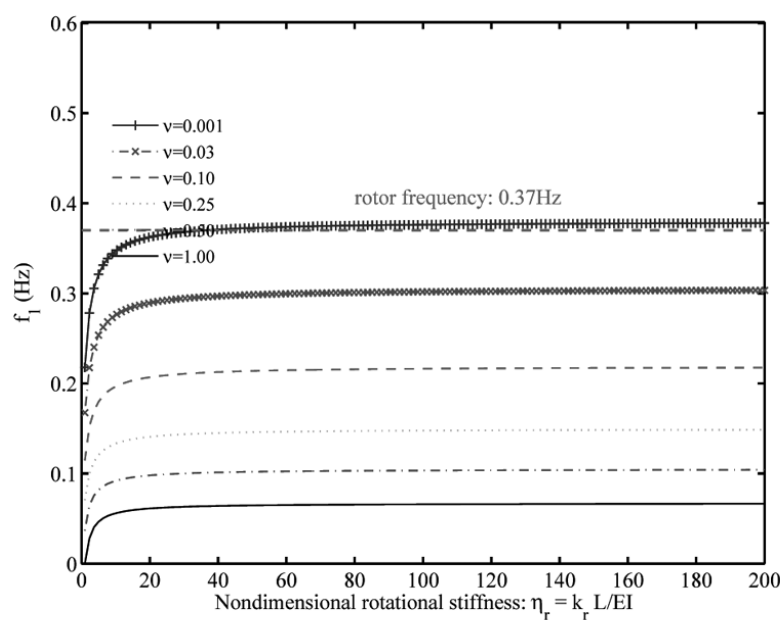

(c) $\eta_{l}=10$

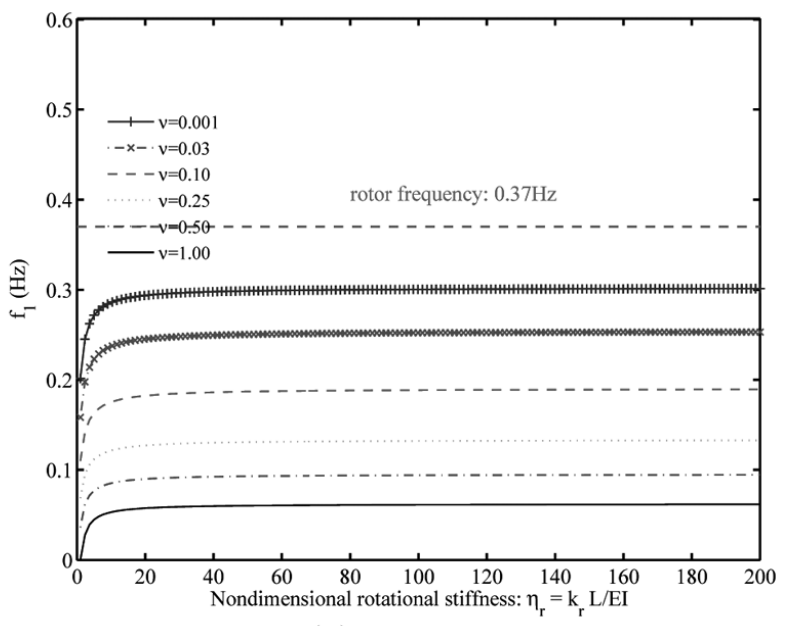

(b) $\eta_{l}=5$

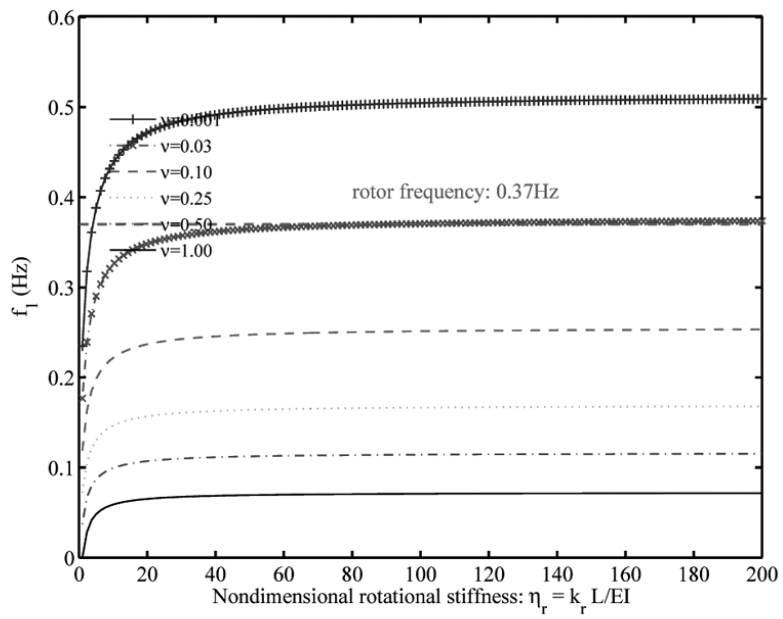

(d) $\eta_{l}=100$

Fig. 7. The variation of the first natural frequency of the wind turbine with respect to the nondimensional rotational foundation stiffness $\eta_{r}$ for different values of nondimensional axial load $\nu$. Four fixed values of the nondimensional lateral stiffness $\eta_{l}$ are considered in the four subplots. The rotor frequency $\varpi=0.37 \mathrm{~Hz}$ is shown by a dashed line in the diagram.

The model wind turbine blades are constructed from a lightweight wood and are attached to a $24 \mathrm{v}$ electric motor powered by a DC power supply which is then attached to the tower. The effect of rotor frequency $(1 P)$ is simulated through the revolutions of the blades powered by the motor. A displacement controlled actuator has been employed which acts at a point in the tower to simulate the wind loading on the structure: mainly the blade passing frequency (3P). Monopile type of foundation has been used as shown in Fig. 1(A). The lateral foundation stiffness $\left(k_{l}\right)$ and the rotational foundation stiffness $\left(k_{r}\right)$ are evaluated by direct measurements as discussed below. The wind turbine was founded on saturated sand. The test procedures adopted to obtain $k_{r}$ and $k_{l}$ are as follows:

- Static moment test to measure $k_{r}$ : The rotational stiffness of the foundation $\left(k_{r}\right)$ was measured by applying a moment at the pile head and measuring the slope caused by it. The pile was carefully installed in the soil by pushing and was allowed sufficient time to reach steady state. A known moment was applied at the top of the pile and the rotation of the pile head was obtained by measuring the lateral displacements of two $40 \mathrm{~mm}$ spaced dial gauges. Typical results from a test are shown in Fig. 12. The initial tangent is considered as the stiffness as we are interested in small amplitude vibration. 


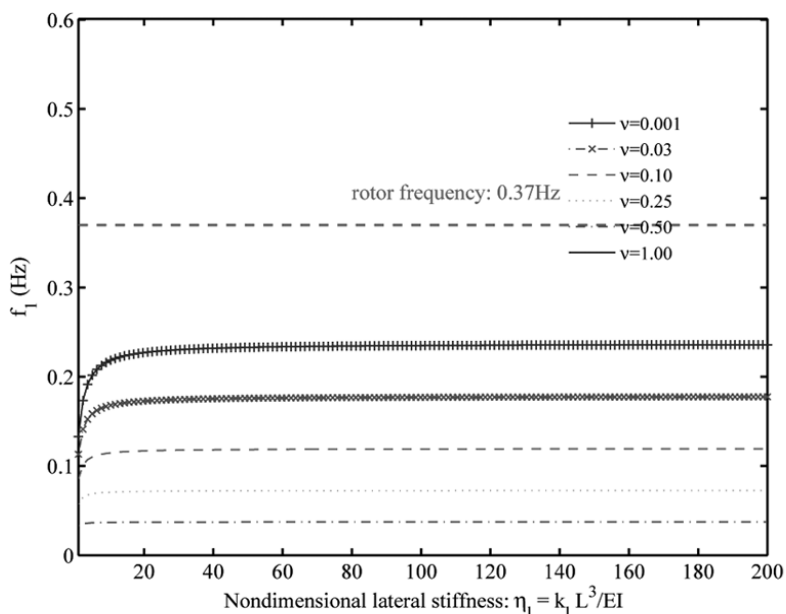

(a) $\eta_{r}=1$

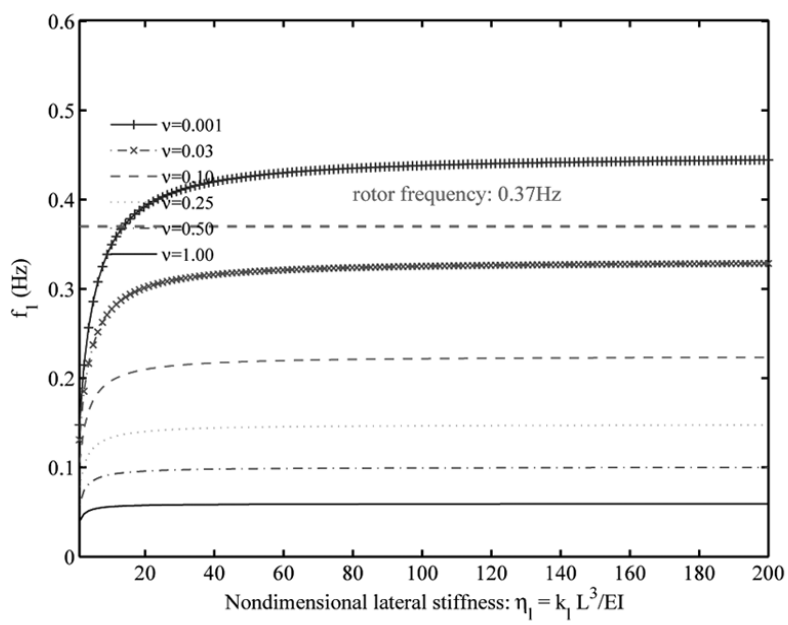

(c) $\eta_{r}=10$

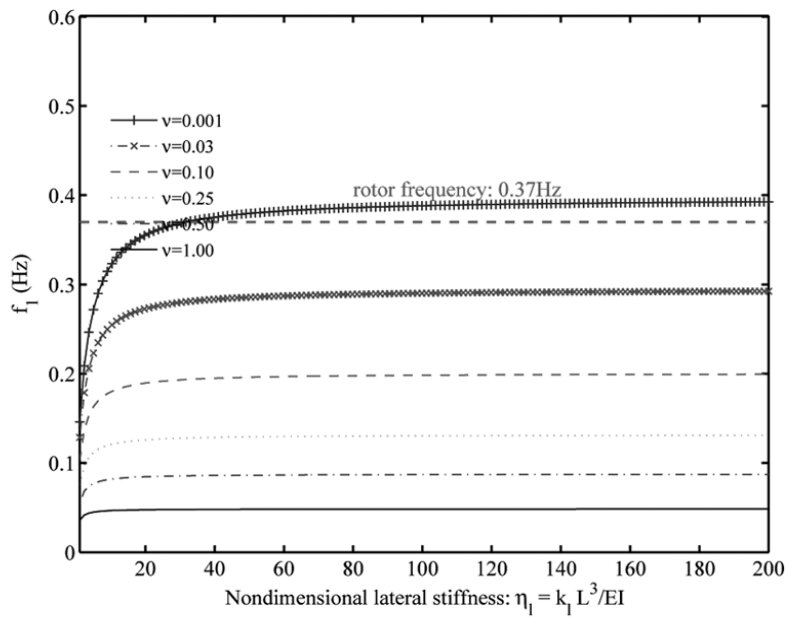

(b) $\eta_{r}=5$

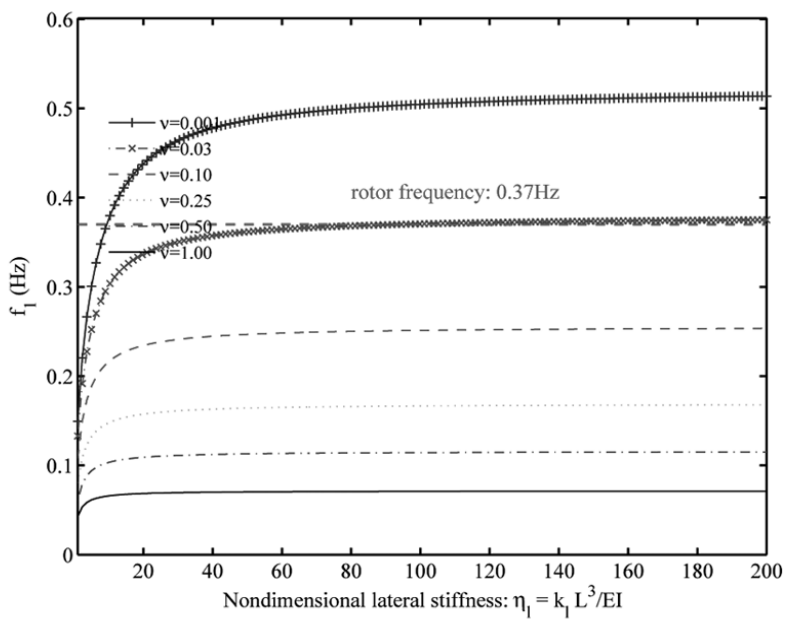

(d) $\eta_{r}=100$

Fig. 8. The variation of the first natural frequency of the wind turbine with respect to the nondimensional lateral stiffness $\eta_{l}$ for different values of nondimensional axial load $\nu$. Four fixed values of the nondimensional rotational foundation stiffness $\eta_{r}$ are considered in the four subplots. The rotor frequency $\varpi=0.37 \mathrm{~Hz}$ is shown by a dashed line in the diagram.

- Static test to measure $k_{l}$ : The horizontal stiffness of the foundation $\left(k_{l}\right)$ was measured by carrying a lateral push over test on the embedded pile in the soil. Lateral load was applied at the top of the pile and the lateral displacements of the pile were measured using a dial gauge. The load displacement curve is plotted and the initial tangent gives the value of $k_{l}$. Figure 13 shows typical test results.

The values of the soil-structure interaction parameters $\eta_{r}$ and $\eta_{l}$ can be obtained by normalizing $k_{r}$ and $k_{l}$ obtained in this way.

\subsection{Analytical approaches}

This section discusses the two widely used analytical methods that can be used to obtain the static foundation stiffness for a monopile type of foundation.

- Subgrade reaction approach or the Winkler spring approach: In this approach the pile is a modelled as beam elements and the soil is modelled as a set of non-linear independent springs often known as p-y springs ('p' refers to the soil reaction force to the pile deformation ' $y$ ' at a certain depth). Methods to construct $p$-y curves 


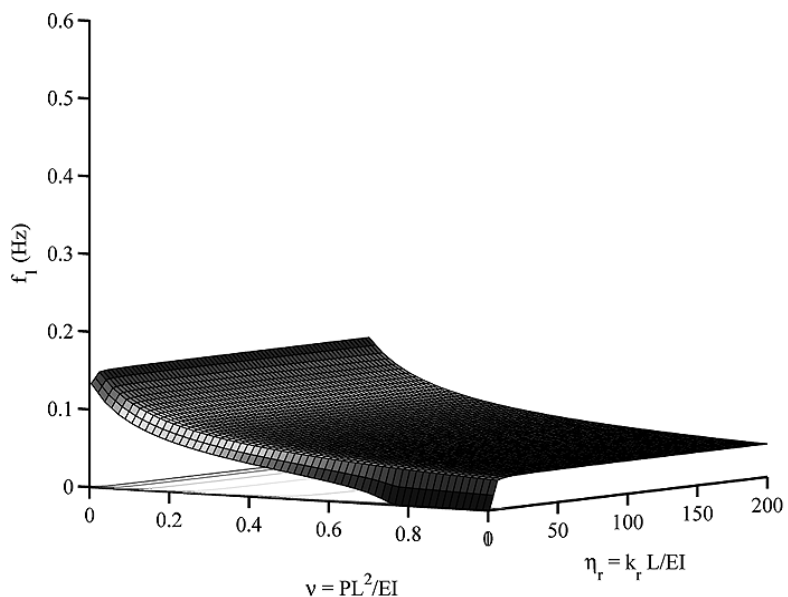

(a) $\eta_{l}=1$

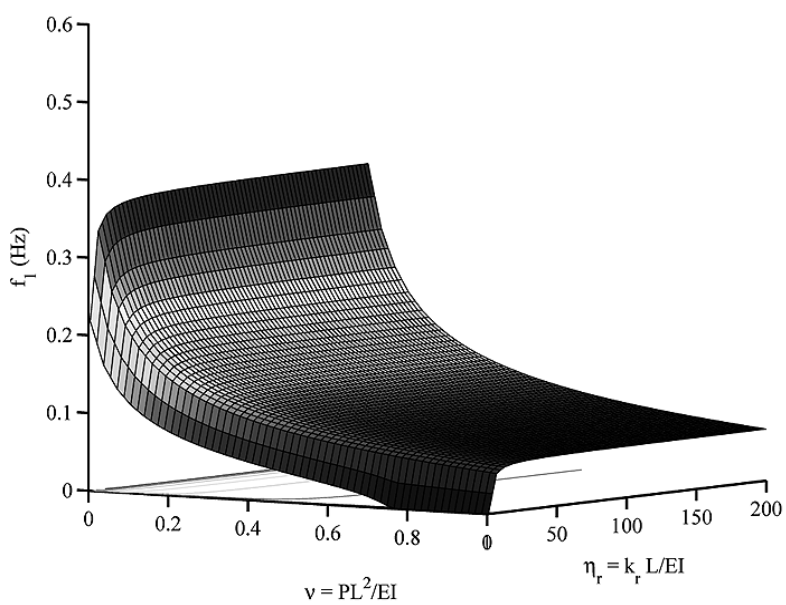

(c) $\eta_{l}=10$

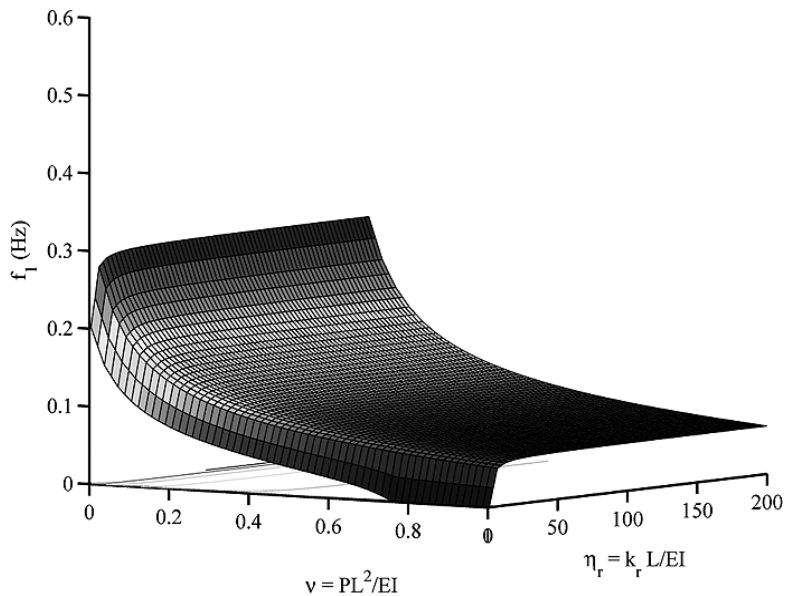

(b) $\eta_{l}=5$

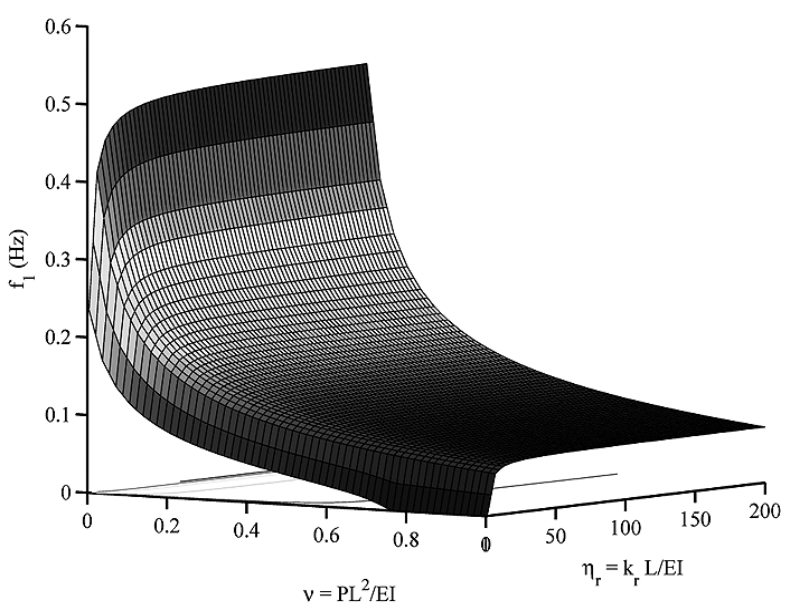

(d) $\eta_{l}=100$

Fig. 9. The variation of the first natural frequency of the wind turbine with respect to the nondimensional axial load $\nu$ and nondimensional rotational foundation stiffness $\eta_{r}$. Four fixed values of the nondimensional lateral stiffness $\eta_{l}$ are considered in the four subplots.

for various types soils can be found in Matlock [21], Reese and Welch [27], API [4], Bhattacharya et al. [7]. This method is very popular and is widely used due to its success in the offshore oil and gas industry.

- Continuum approach or the finite element approach: In this approach, the pile and the soil are modelled as a continuum element. Though this is a very sophisticated method, this is seldom used in practice due to the computational time necessary for a standard routine pile design and also due to the lack of appropriate constitutive models for all types of soil encountered in practice.

Based on the work of Matlock and Reese [22], closed-form expressions developed by Fleming et al. [14] to obtain the ground line deflection and the rotation of a pile can be given as

$$
\begin{aligned}
u & =\sqrt{2} \frac{H}{k}\left(\frac{L_{c}}{4}\right)^{-1}+\frac{M}{k}\left(\frac{L_{c}}{4}\right)^{-2} \\
\text { and } \quad \theta & =\frac{H}{k}\left(\frac{L_{c}}{4}\right)^{-2}+\sqrt{2} \frac{M}{k}\left(\frac{L_{c}}{4}\right)^{-3}
\end{aligned}
$$

In the above expressions $u$ is the ground line pile head deflection, $\theta$ is the ground line pile head rotation, $H$ is the pile head lateral load, $M$ is the pile head moment and $L_{c}=$ Critical length of the pile defined as the length beyond which the pile behaves as if it were infinitely long. Following Fleming et al. [14], the expression for $L_{c}$ is given by 


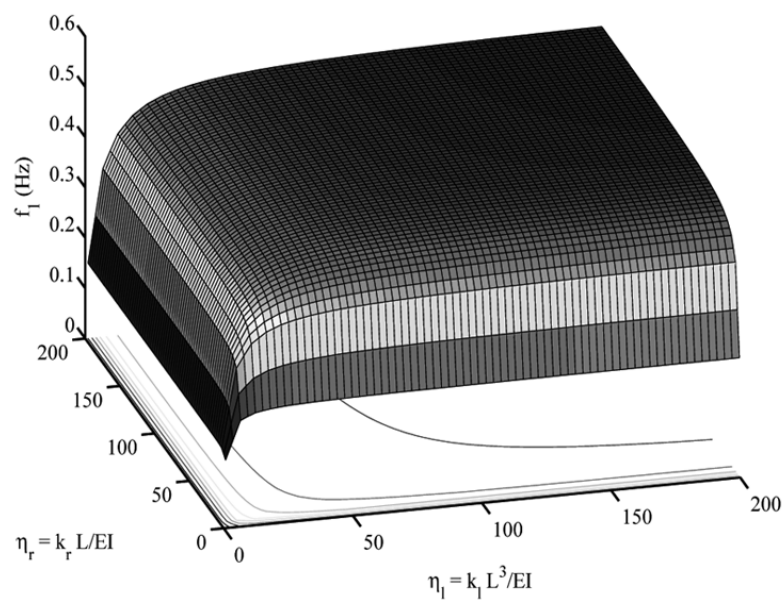

(a) $\nu=0.001$

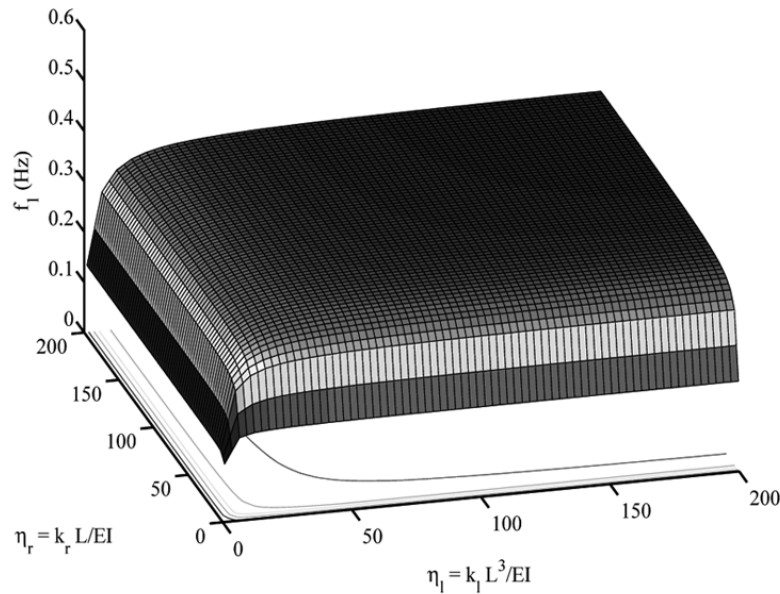

(c) $\nu=0.03$

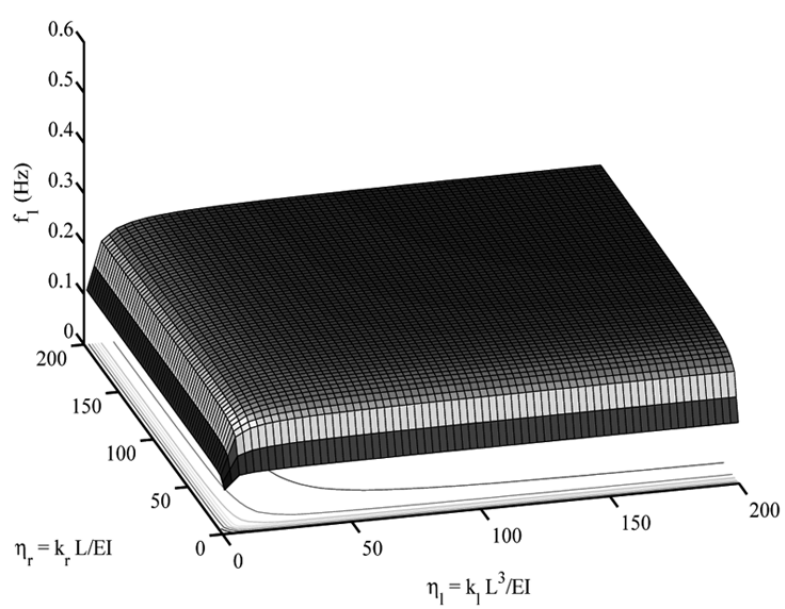

(b) $\nu=0.1$

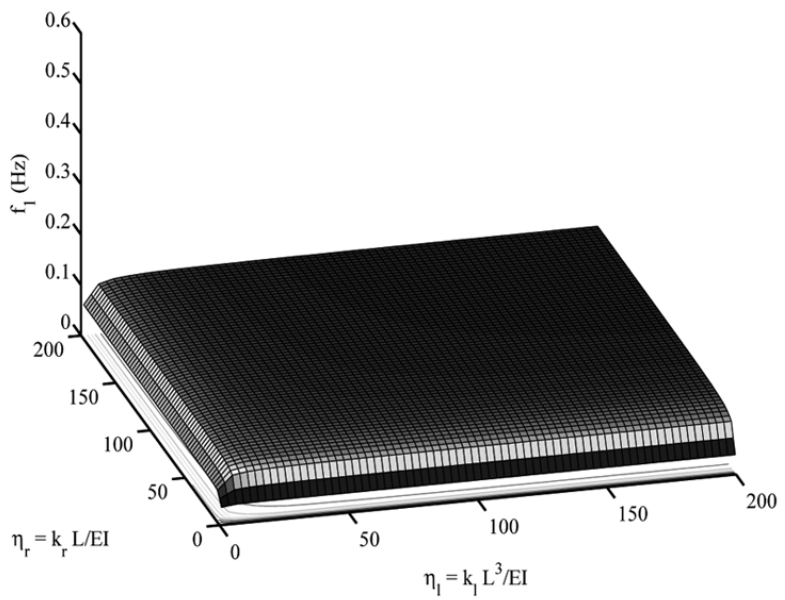

(d) $\nu=0.5$

Fig. 10. The variation of the first natural frequency of the wind turbine with respect to the nondimensional lateral stiffness $\eta_{l}$ and nondimensional rotational foundation stiffness $\eta_{r}$. Four fixed values of the nondimensional axial load $\nu$ are considered in the four subplots.

$$
L_{c}=4\left(\frac{E I_{p}}{4 k}\right)^{1 / 4}
$$

where $E I_{p}$ is the bending rigidity of the pile and $k$ is the equivalent modulus of subgrade reaction (spring stiffness) given by

$$
\frac{k}{G} \approx 10\left(\frac{E_{p}}{G}\right)^{-0.14}
$$

Here $G$ is the shear Modulus of the soil and $E_{p}$ is the equivalent modulus of elasticity of the pile. Equation (57) is based on the interpretation of the work carried out by Baguelin et al. [5] and presented by Randolph and Steward [26].

An expression of $k_{l}$, that is, the required translational foundation stiffness can be estimated from Eq. (54) by substituting $M=0$ and noting that $H=k_{l}$ when $u=1$. Similarly, by substituting $H=0$ in Eq. (55) and noting that $M=k_{r}$ when $\theta=1$. As a result we have

$$
k_{l}=\frac{k}{\sqrt{2}}\left(\frac{4}{L_{c}}\right)^{-1}
$$




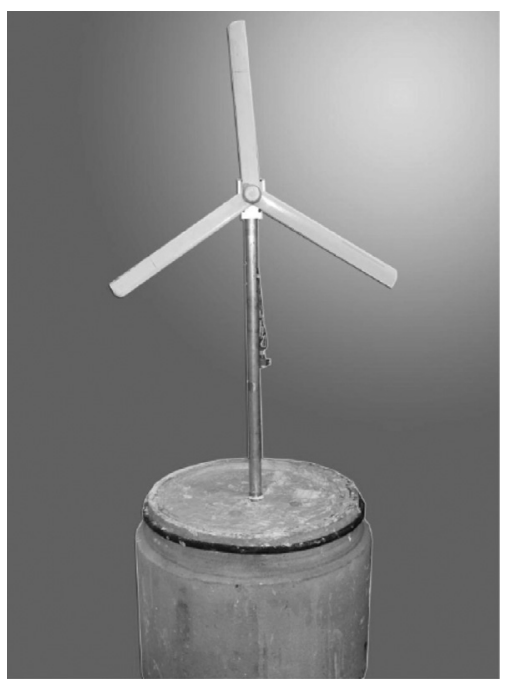

Fig. 11. The model wind turbine. The properties are $-E I$ (Tower): $2.125 \times 10^{9} \mathrm{Nmm}^{2} ; E I$ (Pile): $3.18 \times 10^{8}$ Nmm ${ }^{2}$, Length of the tower: $1.0 \mathrm{~m}$; Length of the pile: $0.5 \mathrm{~m}$.

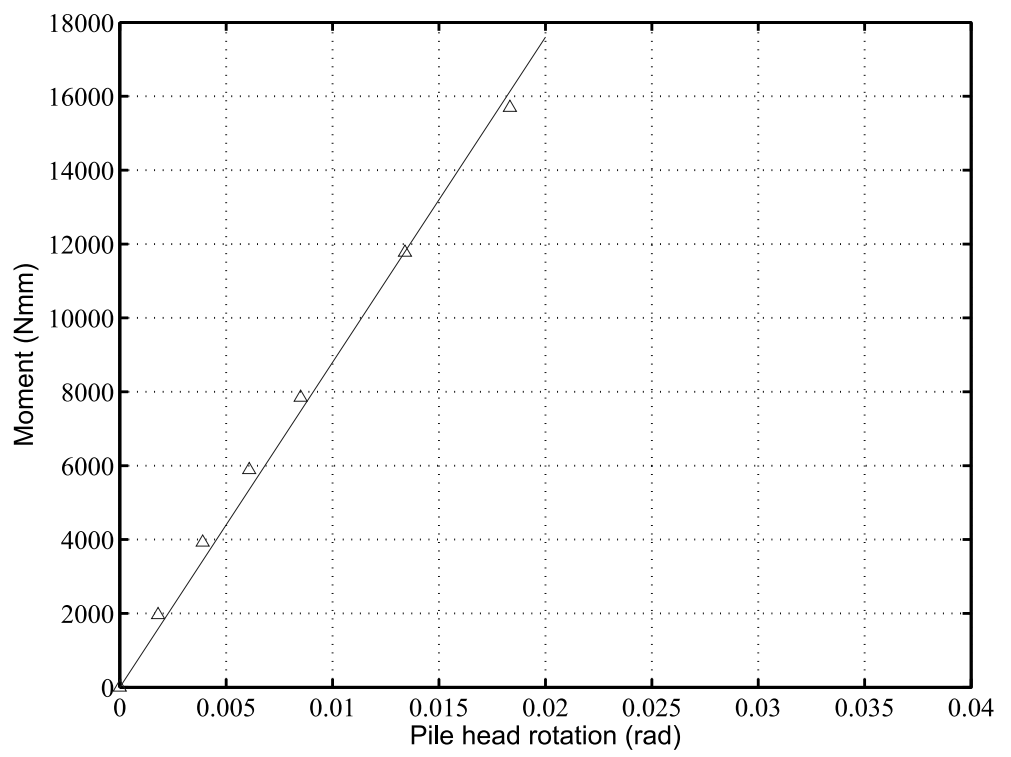

Fig. 12. Experimentally obtained values of $k_{r}$ for wind turbine founded on saturated sand; linearized value $k_{r}=0.87 \mathrm{MN} / \mathrm{mm}$.

$$
\text { and } k_{r}=\frac{k}{\sqrt{2}}\left(\frac{4}{L_{c}}\right)^{-3}
$$

These expressions are applied to three examples of field piles and the results are summarized in Table 2.

\section{Validation of the proposed approach}

In the previous section one experimental and two numerical methods have been suggested to obtain the soilstructure interaction parameters $\eta_{r}$ and $\eta_{l}$. The analytical method is applied for three wind turbines and the values of these constants were obtained. Here these values, together with further details given in Table 3, are used to obtain the necessary nondimensional parameters. Out of the three data sets presented in Table 3, Lely A2 and Irene 
Table 2

Typical values of the soil structure interaction parameters $k_{r}$ and $k_{l}$ obtained for there real wind turbines. Equations (58) and (59) are used to obtain these values

\begin{tabular}{|c|c|c|c|c|}
\hline $\begin{array}{l}\text { Project, soil profile and ref- } \\
\text { erence pile diameter }\end{array}$ & Pile $E I$, length & Spring stiffness of the soil $(k)$ & $\begin{array}{l}\text { Critical length of } \\
\text { the pile }\left(L_{c}\right)\end{array}$ & $\begin{array}{l}\text { Calculated values of } \\
k_{r} \text { and } k_{l}\end{array}$ \\
\hline $\begin{array}{l}\text { North Hoyle: 2MW ( } 30 \\
\text { turbines), Irish sea - Liver- } \\
\text { pool bay Carter (2007) The } \\
\text { upper seabed layers com- } \\
\text { prises variations of sand } \\
\text { and clay layers (firm to } \\
\text { hard clay to very stiff sandy } \\
\text { clay). Below is the mud- } \\
\text { stone or sandstone. }\end{array}$ & $\begin{array}{l}4 \mathrm{~m} \text { diameter, } 33 \mathrm{~m} \text { pene- } \\
\text { tration below seabed. } 30- \\
70 \mathrm{~mm} \text { wall thickness } E I \\
\text { varies between } 158 \mathrm{GNm}^{2} \\
369 \mathrm{GNm}^{2}\end{array}$ & $\begin{array}{l}\text { For a single value of } 230 \mathrm{MPa} \\
\text { as a characteristic shear modu- } \\
\text { lus of the soil } k \text { ranges between } \\
1.33 \mathrm{GPa}(30 \mathrm{~mm} \text { thick section) } \\
\text { to } 1.18 \mathrm{GPa} \text { (for } 70 \mathrm{~mm} \text { thick } \\
\text { section). }\end{array}$ & $\begin{array}{l}13.2 \mathrm{~m} \text { to } 16.8 \mathrm{~m} \\
\text { For } 30 \mathrm{~mm} \text { thick } \\
\text { and } 70 \mathrm{~mm} \text { thick } \\
\text { section } \\
\text { respectively. }\end{array}$ & $\begin{array}{l}k_{l} \text { is estimated to be } \\
\text { varying between } 3100 \\
\mathrm{MN} / \mathrm{m} \text { to } 3500 \mathrm{MN} / \mathrm{m} \text {. } \\
\text { Similarly, } k_{r} \text { varies } \\
\text { between } 33.8 \mathrm{GNm} / \\
\text { rad to } 62.1 \mathrm{GNm} / \mathrm{rad} \text {. }\end{array}$ \\
\hline $\begin{array}{l}\text { Lely(A2) - inland sea Ijs- } \\
\text { selmeer (the Netherlands) } \\
\text { Zaaijer [30] Pile passes } \\
\text { through soft layer to stiffer } \\
\text { sandy layer. }\end{array}$ & $\begin{array}{l}3.7 \mathrm{~m} \text { diameter pile } 20.9 \mathrm{~m} \\
\text { long. } 35 \mathrm{~mm} \text { wall thick- } \\
\text { ness. } E I: 146 \mathrm{GNm}^{2}\end{array}$ & $\begin{array}{l}\text { For a single value of } 53 \mathrm{MPa} \\
\text { as a characteristic shear modu- } \\
\text { lus of the soil corresponding to } \\
180 \mathrm{~m} / \mathrm{s} \text { shear wave velocity of } \\
\text { the soil, } k \text { is about } 233 \mathrm{MPa} \text {. }\end{array}$ & $20.02 \mathrm{~m}$ & $\begin{array}{l}k_{l} \text { is about } 830 \mathrm{MN} / \mathrm{m} \\
k_{r} \text { is about } 20.6 \mathrm{GNm} / \\
\mathrm{rad} .\end{array}$ \\
\hline $\begin{array}{l}\text { Irene Vorrink- inland sea } \\
\text { Ijsselmeer (the Nether- } \\
\text { lands) Zaaijer [30] Pile } \\
\text { passes through soft layer to } \\
\text { stiffer sandy layer. }\end{array}$ & $\begin{array}{l}3.5 \mathrm{~m} \text { diameter } 19 \mathrm{~m} \text { long. } \\
28 \mathrm{~mm}^{2} \text { wall thickness. } E I \text { : } \\
99 \mathrm{GNm}^{2}\end{array}$ & $\begin{array}{l}\text { For a single value of } 53 \mathrm{MPa} \\
\text { as a characteristic shear modu- } \\
\text { lus of the soil corresponding to } \\
180 \mathrm{~m} / \mathrm{s} \text { shear wave velocity of } \\
\text { the soil, } k \text { is about } 238 \mathrm{MPa} \text {. }\end{array}$ & $18.06 \mathrm{~m}$ & $\begin{array}{l}k_{l} \text { is about } 760 \mathrm{MN} / \mathrm{m} \\
k_{r} \text { is about } 15.5 \mathrm{GNm} / \\
\mathrm{rad} .\end{array}$ \\
\hline
\end{tabular}

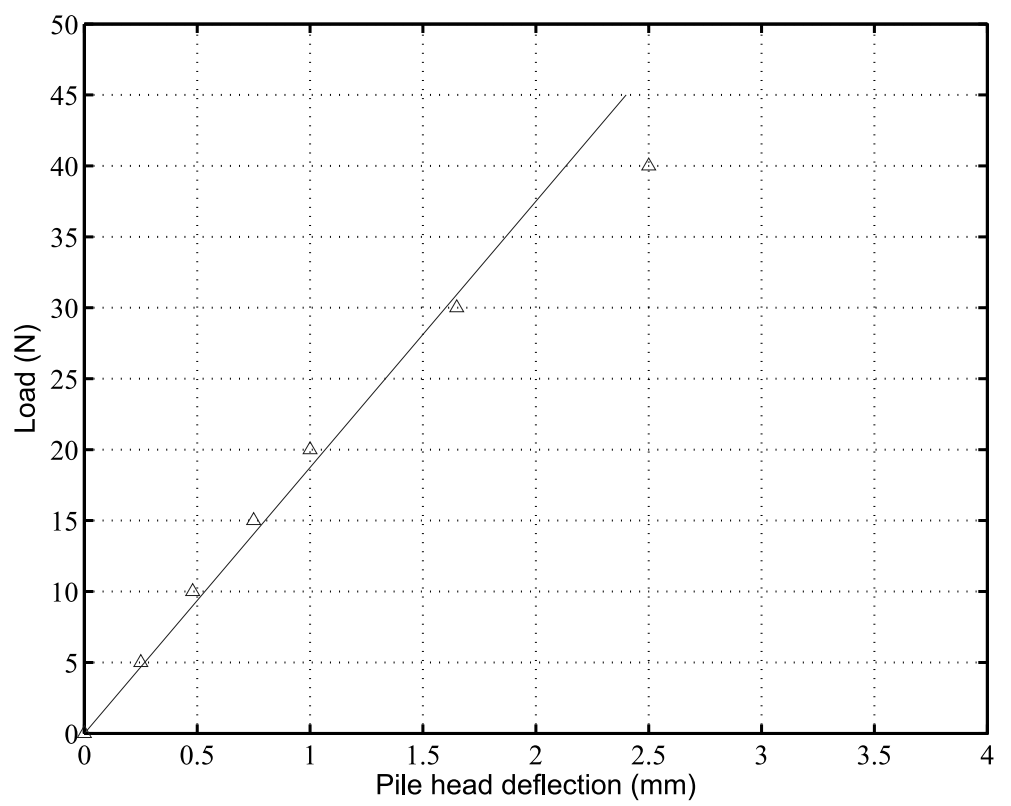

Fig. 13. Experimentally obtained values of $k_{l}$ for wind turbine founded on saturated sand; linearized value $k_{l}=18.75 \mathrm{~N} / \mathrm{mm}$.

Vorrink are two bladed turbines installed for the purpose of study whereas North Hoyle is commercial offshore wind turbine. The nondimensional parameters, measured and predicted natural frequencies of the three wind turbines are shown in Table 4. Out of the three turbines considered, field measurements are available for two turbines only. The predicted natural frequency is reasonably close to the measured frequency. The percentage errors are respectively $14 \%$ and $16 \%$. In addition to the simplified physical assumptions, average geometric properties (such as diameter ad thickness) are used in the proposed approach. This hightlights the fact that a quick estimation of the fundamental natural frequency of the wind turbine system can be obtained using the method proposed in this paper. 
Table 3

Details of the towers and top masses required to compute the non-dimensional parameters

\begin{tabular}{ll}
\hline Case study & Details of the tower \\
\hline North Hoyle, 2.0 MW capacity & Rotor Diameter: $80 \mathrm{~m}$ \\
Vestas V80 upwind 3-bladed wind & Hub Height: $70 \mathrm{~m}$ \\
turbine & Top mass (Mass of Nacelle and rotor) $=100,000 \mathrm{~kg}$ \\
& Tower: $130,000 \mathrm{~kg}$ \\
& Water depth: 7 to $11 \mathrm{~m}$ \\
& Average $E I$ of the tower (estimated) $=133 \mathrm{G} \mathrm{Nm}^{2}$ \\
& Rotor Dia $=40.77$ \\
A2: NM41 Type $500 \mathrm{~kW}$ Turbine, & Hub Height $=41.5$ \\
Lely island & Top Mass $=32,000 \mathrm{~kg}$ \\
& Water depth $=4.6 \mathrm{~m}$ \\
& Tower Diameter $=3.2 \mathrm{~m}$ at the base and $1.9 \mathrm{~m}$ at the top and the wall thickness \\
& is $12 \mathrm{~mm}\left(\right.$ equivalent $E I$ considering the effect of tapering is $\left.22 \mathrm{GNm}{ }^{2}\right)$ \\
& Rotor Dia $=43 \mathrm{~m}$ \\
& Hub Height $=51 \mathrm{~m}$ \\
Irene Vorrink- NTK 600 Type Tur- & Top Mass $=35,700 \mathrm{~kg}$ \\
bine. Capacity is $600 \mathrm{~kW}$ & Water depth: 3 to $3.8 \mathrm{~m}$ \\
& Tower Diameter: $1.7 \mathrm{~m}$ at the top to $3.5 \mathrm{~m}$ at the bottom, Wall thickness \\
& varies: $8 \mathrm{~mm}$ to $14 \mathrm{~mm}$ (equivalent $E I$ considering the effect of tapering is \\
& 21.5 GNm $\left.{ }^{2}\right)$ \\
\hline
\end{tabular}

Table 4

Nondimensional parameters, measured and predicted natural frequencies of the three wind turbines

\begin{tabular}{llllllll}
\hline Name of the turbine & $\nu$ & $\eta_{r}$ & $\eta_{l}$ & $\alpha$ & $c_{0}$ & $\begin{array}{l}\text { Measured } \\
\text { frequency }\end{array}$ \\
\hline A2-Lely & 0.033 & 38.88 & 2698 & 1.0178 & $3.13 \mathrm{rad} / \mathrm{s}$ & $0.634 \mathrm{~Hz}$ & $0.7404 \mathrm{~Hz}$ \\
frequency & & $0.546 \mathrm{~Hz}$ & $0.4565 \mathrm{~Hz}$ \\
Irene Vorrink & 0.030 & 39.64 & 5880 & 1.144 & $2.035 \mathrm{rad} / \mathrm{s}$ & Not known & $0.3451 \mathrm{~Hz}$ \\
North Hoyle & 0.0114 & 28 & 11775 & 0.76 & $1.323 \mathrm{rad} / \mathrm{s}$ & \\
\hline
\end{tabular}

\section{Conclusions}

The dynamics of flexible turbine towers on elastic end supports have been investigated. The consideration of elastic end supports, used to take account of the structure-foundation interaction, is crucial for offshore wind turbines and have received little attention in literature. A distributed parameter linear dynamic model using the EulerBernoulli beam theory with axial load, elastic support stiffness and top mass with rotary inertia is considered. The non-dimensional parameters necessary to understand the dynamic behavior have been identified. These parameters are nondimensional axial force $(\nu)$, nondimensional rotational foundation stiffness, $\left(\eta_{r}\right)$, nondimensional lateral foundation stiffness, $\left(\eta_{l}\right)$, mass ratio between the rotor-blade assembly and the turbine tower $(\alpha)$, nondimensional radius of gyration of the turbine tower $(\mu)$. The closed-form expression of the characteristic equation governing the natural frequencies of the system has been derived. An experimental and two numerical methods have been suggested to obtain the soil-structure interaction parameters $\eta_{r}$ and $\eta_{l}$. Experimental results on saturated sand show that the linear model proposed for these parameters can be used when the rotation and the deflection of the pile-head is small.

The analytical results derived here have been illustrated by numerical examples. The proposed approach was applied to three real-life wind turbines and the results were compared with field measurements. It was observed that the predicted and measured natural frequencies were reasonably close. As expected, the natural frequency of the turbine tower decreases with decreasing stiffness values of the (foundation) support and increasing values of the axial load. One needs to check the condition of the underlying foundation and weight of the rotor-blade assembly. The natural frequency of the system should be well separated from the rotor frequency and the blade passing frequencies. Using the new expressions derived in the paper, analysts could quickly predict the natural frequencies for various parameter values and design the turbine tower such that the resulting natural frequencies lie within the desired safe frequency bands. 


\section{References}

[1] S. Adhikari, Rates of change of eigenvalues and eigenvectors in damped dynamic systems, AIAA Journal 37 (1999), $1452-1458$.

[2] S. Adhikari, Calculation of derivative of complex modes using classical normal modes, Computer and Structures 77 (2000), $625-633$.

[3] S. Adhikari and S. Bhattacharya, Dynamic instability of pile-supported structures in liquefiable soils during earthquakes, Shock and Vibration 15 (2008), 665-685.

[4] API, Recommended Practice for Planning, Designing, and Constructing Fixed Offshore Platforms-Working Stress Design, Ver 21., American Petroleum Institute, USA, 2000.

[5] S.Y. Baguelin F. and R. Frank, Theoretical study of lateral reaction mechanism of piles, Géotechnique 27 (1977), 405-434.

[6] S. Bhattacharya, S. Adhikari and N.A. Alexander, A simplified method for unified buckling and dynamic analysis of pile-supported structures in seismically liquefiable soils, Soil Dynamics and Earthquake Engineering 29 (2009), 1220-1235.

[7] S. Bhattacharya, T.M. Carrington and T. Aldridge, Design of FPSO piles against storm loading, Proceedings of the Offshore Technology Conference, Houston, TX (2006), paper Number 17861.

[8] B. Byrne and G. Houlsby, Foundations for offshore wind turbine, Phil Trans R Soc Lond A 361 (2003), 2909-2930.

[9] A.G. Davenport, Transcendental eigenvalue problem and its applications, Quarterly Journal of Royal Meteorological Society 87 (1961), 194-211.

[10] I. Elishakoff, Eigenvalues of Inhomogeneous Structures: Unusual Closed-Form Solutions, CRC Press, Boca Raton, FL, USA, 2005.

[11] I. Elishakoff, Essay on the contributors to the elastic stability theory, Meccanica 40 (2005), 75-110.

[12] I. Elishakoff and V. Johnson, Apparently the first closed-form solution of vibrating inhomogeneous beam with a tip mass, Journal of Sound and Vibration 286 (2005), 1057-1066.

[13] I. Elishakoff and A. Perez, Design of a polynomially inhomogeneous bar with a tip mass for specified mode shape and natural frequency, Journal of Sound and Vibration 287 (2005), 1004-1012.

[14] W. Fleming, A. Weltman, M.F. Randolph and W. Elson, Piling Engineering, John Wiley and Sons, New York, USA, 1992.

[15] M. Géradin and D. Rixen, Mechanical Vibrations, John Wiely \& Sons, New York, NY, second edition, 1997, translation of: Théorie des Vibrations.

[16] M. Gurgoze, On the eigenfrequencies of a cantilever beam carrying a tip spring-mass system with mass of the helical spring considered, Journal of Sound and Vibration 282 (2005), 1221-1230.

[17] M. Gurgoze and H. Erol, On the frequency response function of a damped cantilever simply supported in-span and carrying a tip mass, Journal of Sound and Vibration 255 (2002), 489-500.

[18] D.J. Inman, Engineering Vibration, Prentice Hall PTR, NJ, USA, 2003.

[19] J.M. Jonkman, Dynamics of offshore floating wind turbines-model development and verification, Wind Energy 12 (2009), $459-492$.

[20] E. Kreyszig, Advanced engineering mathematics, John Wiley \& Sons, New York, nine edition, 2006.

[21] H. Matlock, Correlations of design of laterally loaded piles in soft clay, Proceedings of the Offshore Technology Conference, Houston, TX 1 (1970), 577-594.

[22] H. Matlock and L.C. Reese, Generalized solutions for laterally loaded piles, Journal of the Soil Mechanics Division, ASCE 86 (1961), 673-694.

[23] L. Meirovitch, Principles and Techniques of Vibrations, Prentice-Hall International, Inc., New Jersey, 1997.

[24] L. Moskowitz, Estimates of the power spectrums for fully developed seas for wind speeds of 20 to 40 knots, Journal of Geophysical Research 69 (1964), 5161-5179.

[25] H.R. Oz, Natural frequencies of an immersed beam carrying a tip mass with rotatory inertia, Journal of Sound and Vibration 266 (2003), 1099-1108.

[26] M.F. Randolph and D.P. Steward, Manual for the program PYGM, University of Western Australia, Australia, 1999.

[27] L.C. Reese and R.C. Welch, Lateral loading of deep foundations in stiff clay foundation modelling to assess dynamic behaviour of offshore wind turbines, Journal of the Geotechnical Engineering Division, ASCE 101 (1975), 633-649.

[28] D.-P. Tempel and D.-P. Molenaar, Wind turbine structural dynamics - A review of the principles for modern power generation, onshore and offshore, Wind Engineering 26 (2002), 211-220.

[29] J.S. Wu and S.H. Hsu, A unified approach for the free vibration analysis of an elastically supported immersed uniform beam carrying an eccentric tip mass with rotary inertia, Journal of Sound and Vibration 291 (2006), 1122-1147.

[30] M. Zaaijer, Foundation modelling to assess dynamic behaviour of offshore wind turbines, Journal of Applied Ocean Research 28 (2006), 45-57. 

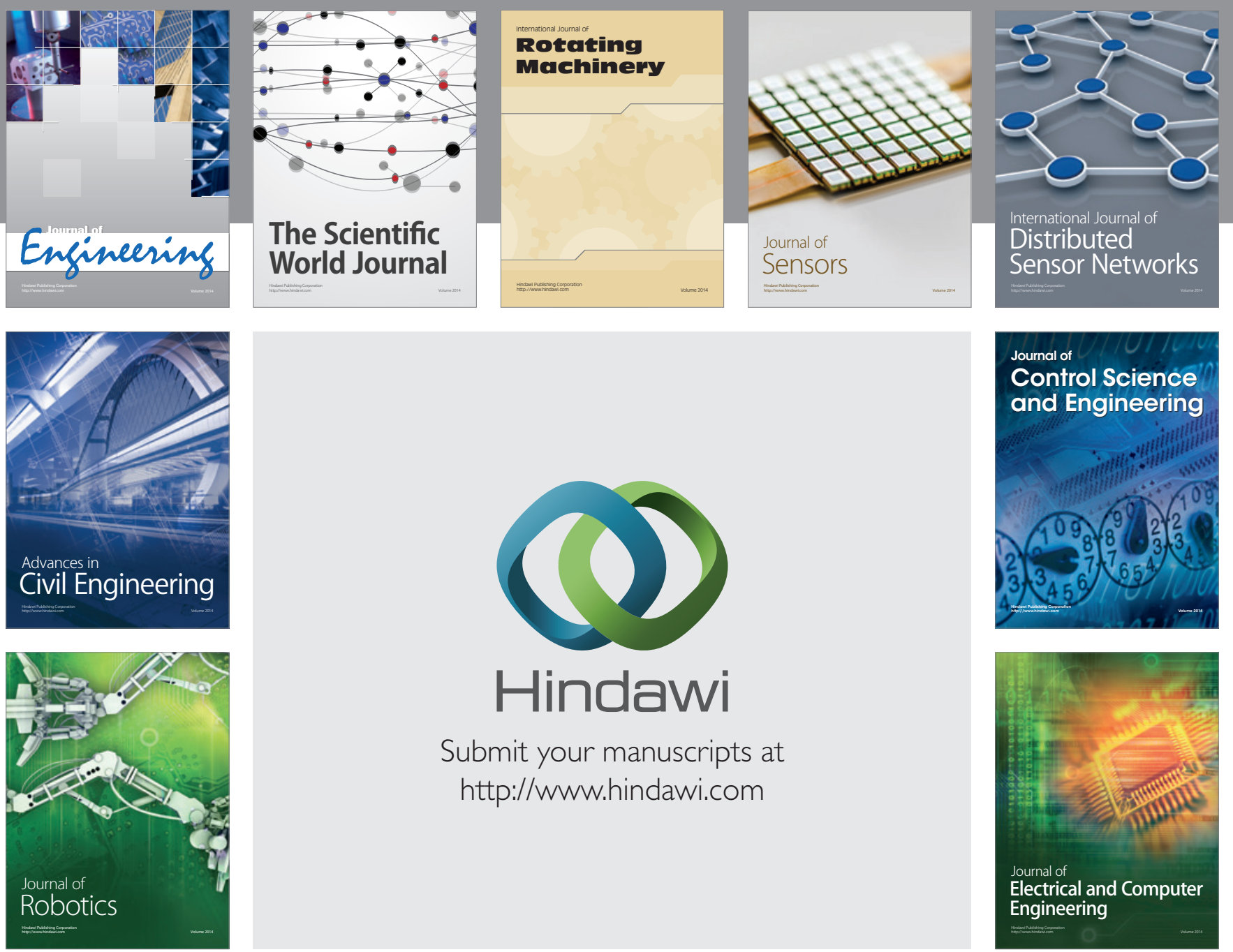

Submit your manuscripts at

http://www.hindawi.com
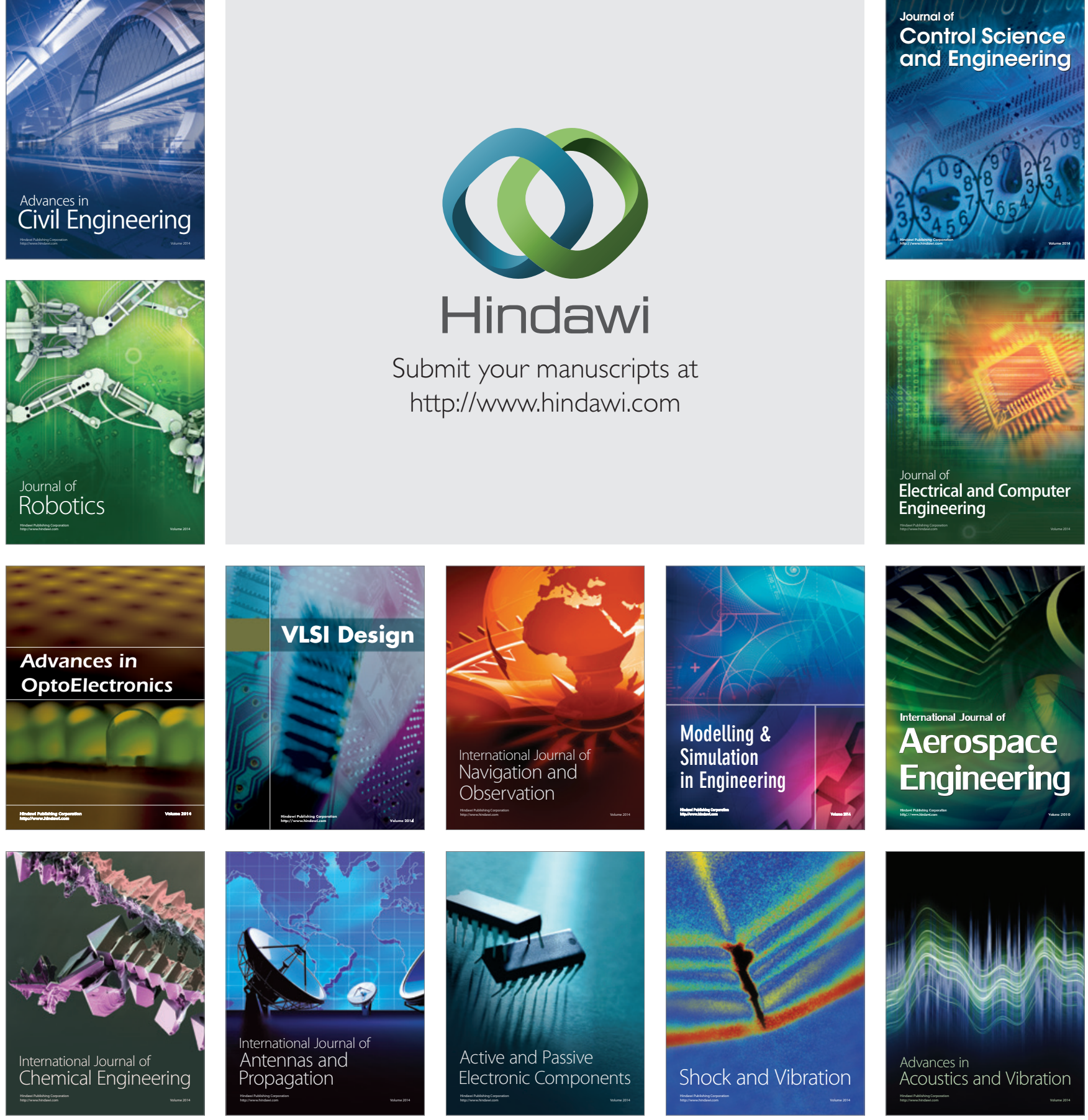